\title{
Sector Coupling in the North Sea Region-A Review on the Energy System Modelling Perspective
}

\author{
Md. Nasimul Islam Maruf \\ Department of Energy and Environmental Management, Europa-Universität Flensburg, 24943 Flensburg, \\ Germany; ni.maruf@uni-flensburg.de; Tel.: +49-461-805-3007
}

Received: 26 September 2019; Accepted: 8 November 2019; Published: 11 November 2019

\begin{abstract}
Sector coupling is one of the emerging topics in recent energy and climate change policy discussions. It can play a significant role in creating the pathway of a renewable-based energy system in the European energy sector. The North Sea region is very likely to play a key role in the transition to a sustainable energy system. Although different energy modelling approaches allow a versatile use, they lead to the problem of an unclear understanding of specific aspects of sector coupling, and the relevance of existing tools and techniques to model and analyze such a system. This paper is aimed at providing a comprehensive understanding of sector coupling and its incorporation in energy system models. Following a thorough literature review on sector coupling and energy system modelling, the paper outlines an approach to select an appropriate tool based on the specific rationales of the research. The paper also presents the open energy modelling framework, 'Oemof', as an open model tool to address the complex challenges of energy systems. The conclusions from the literature review provide a detailed understanding of the concept of sector coupling and indicate that it can be advantageous from the viewpoints of decarbonization, flexibility, network optimization, and system efficiency. To solve the coupling barriers, diversified techno-socio-economic circumstances should be taken into account through the use of model collaboration. It is also demonstrated how a list of appropriate tools for model collaboration can be picked up methodologically from an available wide range of models. Finally, 'Oemof' is hypothesized as a progressive tool to design a sector-coupled and renewable-based energy system in the North Sea region.
\end{abstract}

Keywords: sector coupling; energy system modelling; North Sea energy system; energy transition; open science; Oemof

\section{Introduction}

The advancement of the European Union (EU) energy system from fossil fuels to renewable energy sources (RES) is frequently stated as the "Energy Transition". Such an energy transition is essential to combat climate change, in line with the Paris agreement [1]. The Paris agreement initiated an international framework to keep the increase in global average temperature to well below $2{ }^{\circ} \mathrm{C}$ [2]. This can only be achieved if there is a global energy transition in terms of how energy is supplied, transformed and used. The EU is a front-runner of this transition and is encouraging transition at the international and national levels to achieve a renewable energy-based system. The North Sea (NS) and its adjacent countries (Belgium, Denmark, France, Germany, Netherlands, Norway, Sweden and the United Kingdom), together referred to as the NS region as shown in Figure 1 [3], play a key role in the EU in the transition to a sustainable energy system. Hajer and Pelzer have explained the transition pathway in the NS region using 'techniques of futuring' in their paper [4]. In the synthesis paper from the project 'North Sea Energy (NSE)' program, the role of offshore energy integration to the NS energy system has been thoroughly investigated [5]. The prominent and potential renewable energy technologies for a future energy system in the NS region, for example, hydropower, biomass, 
biogas and other biofuels, heat pumps, battery storage, power-to-hydrogen, etc. have been exhibited in [6]. All these works of literature indicate that the energy production in the NS region will have to go through a radical change from presently being Europe's most significant hub in oil and gas production to becoming one of Europe's important centers for offshore wind production, with the enormous potential of hydro storage capacity in Norway.

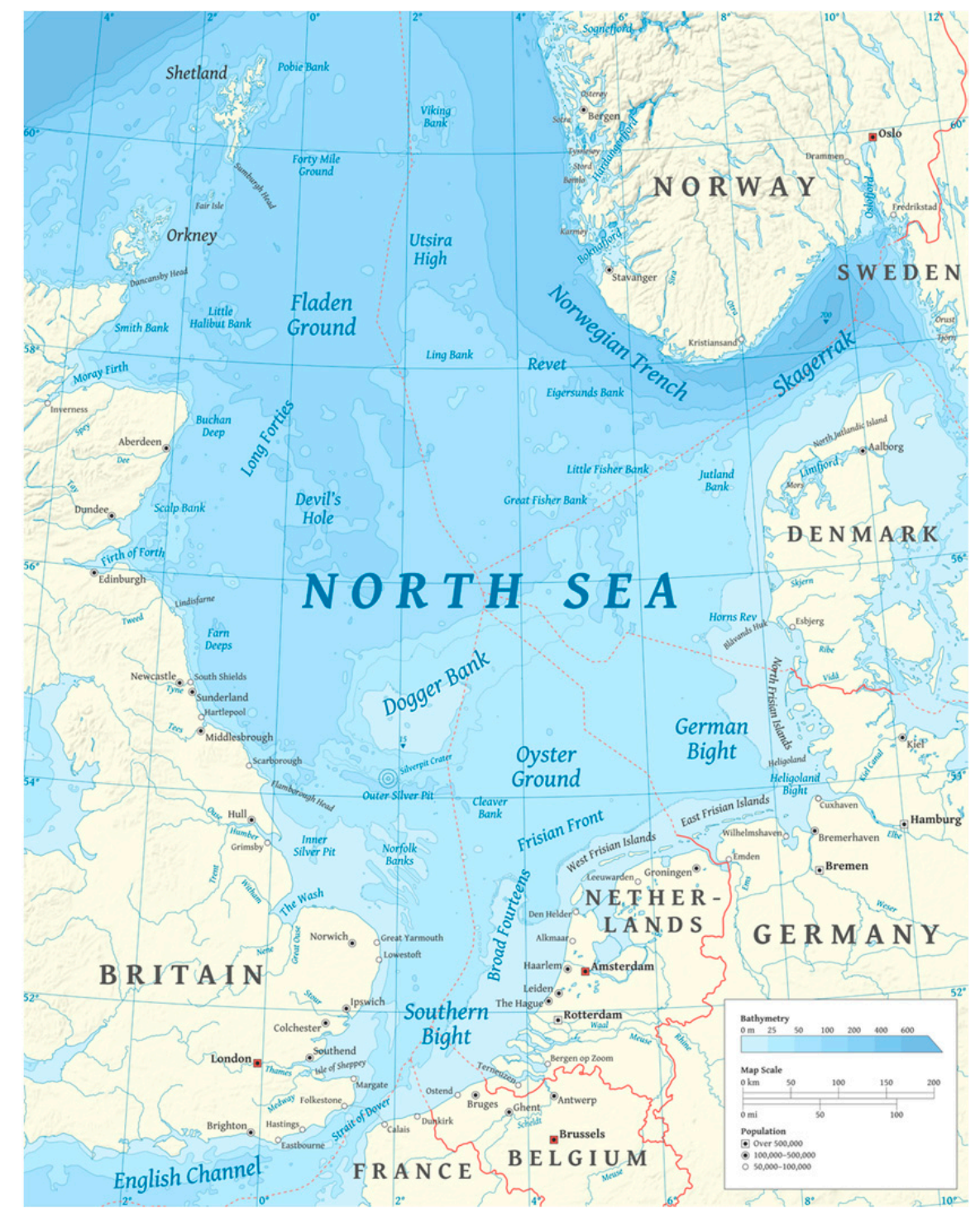

Figure 1. The North Sea and its adjacent countries. Adapted from Wikimedia Commons [3].

In terms of resource consumption and carbon emissions, the NS region has a massive impact in Europe because of its enormous size, oil and gas production, and industrial development. The impact in terms of carbon emission in the NS region can be realized from the extensive Carbon dioxide equivalent $\left(\mathrm{CO}_{2} \mathrm{e}\right)$ emission by the NS countries in Figure 2, which shows the historical greenhouse gas (GHG) emissions with data collected from the United Nations Framework Convention on Climate Change (UNFCCC) (1990-2017) [7]. The data has been visualized using the tool from Climate Watch 2018 [8]. Although the profile exhibits a declining trend since the 1990s, the aggregated emission of the NS countries in 2017 stood at $2.20 \mathrm{Gt} \mathrm{CO}_{2} \mathrm{e}$, which was more than half of the total carbon emission ( $4.1 \mathrm{Gt} \mathrm{CO}_{2} \mathrm{e}$ ) by the EU-28 region in that year [7]. Therefore, the emission by the NS region is very critical from the EU perspective and must be controlled at a significant rate to keep the temperature increment within the Paris agreement ceiling. 


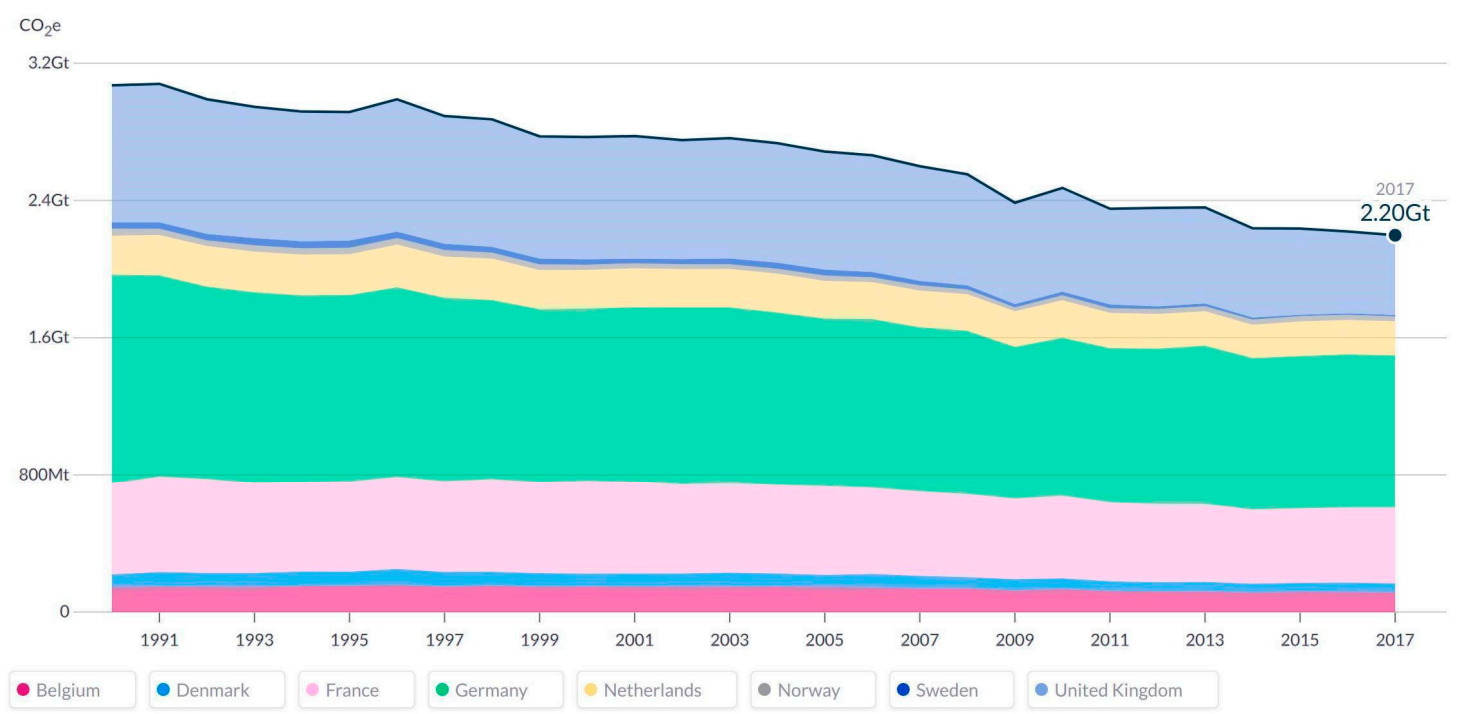

Figure 2. Historical greenhouse gas (GHG) emissions by the North Sea (NS) countries (1990-2017). Adapted from $[7,8]$.

GHG emission is generally driven by high energy demand met by fossil-fueled power plants. This is also true for the energy sectors of the NS countries, which accounts for more than $83 \%$ of the total pollution (1.83 $\mathrm{Gt} \mathrm{CO}_{2} \mathrm{e}$ ) according to 2017 data from UNFCCC [7]. Figure 3, also visualized by using the tool from Climate Watch [8], shows the historical GHG emission in the energy sector from all the NS countries. It is evident from Figure 3 that the countries that are still relying heavily on coal and nuclear for are emitting more (e.g., Germany), and the countries that are using renewables are emitting less (e.g., Denmark, which uses wind as their main resource).

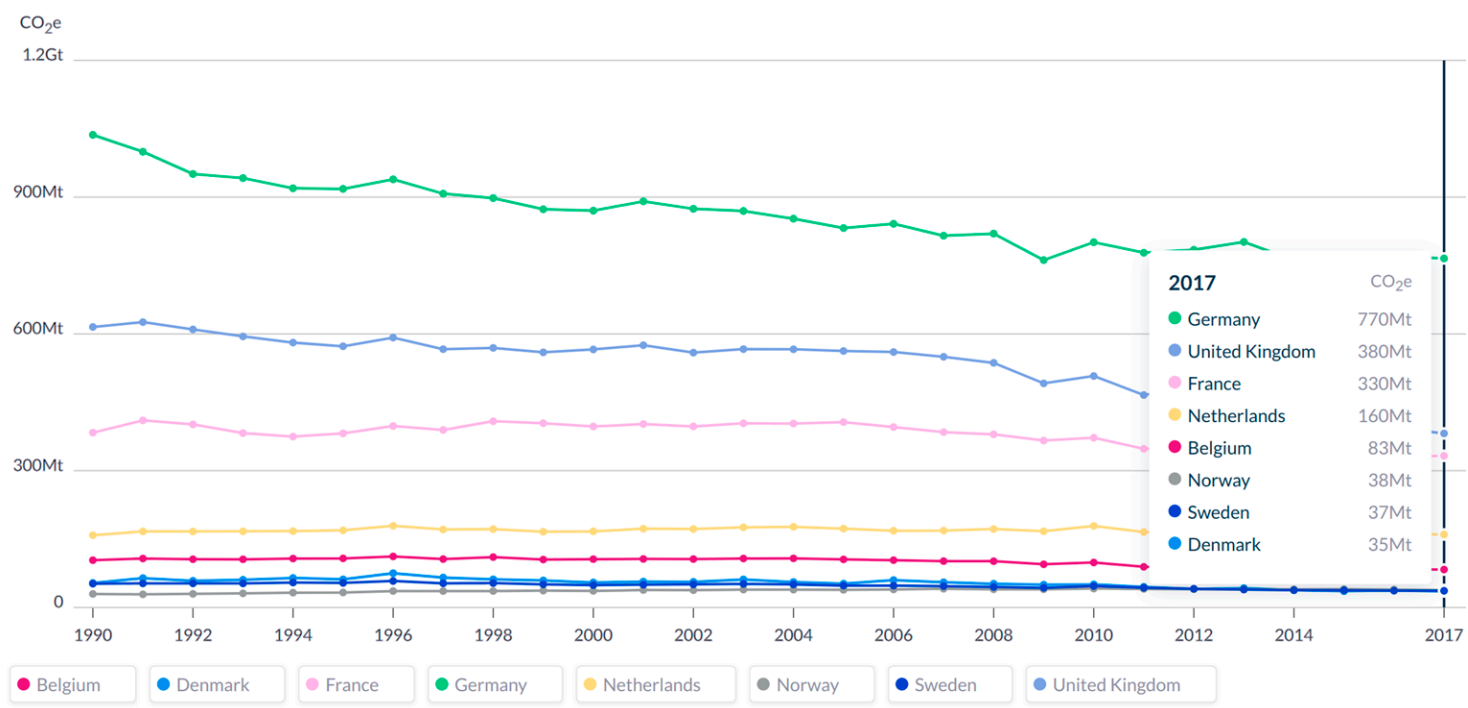

Figure 3. GHG emission in the energy sector by the NS countries (1990-2017). Adapted from [7,8].

\section{Motivation, Objective and Methodology}

\subsection{Motivation}

From the introduction, it is obvious that the NS region needs to play a vital role in the EU's energy transition to a sustainable energy system. The NS region has a large potential for both onshore and offshore wind energy, micro-algae production, and wave energy and ocean thermal energy conversion (OTEC). It also offers opportunities for the deployment of carbon capture and storage (CCS), bio-energy 
facilities, and negative emission facilities (bio-CCS). The energy efficiency and built environment are also improving in the adjacent countries, impacting the supply-demand patterns. The possibilities for sector coupling (SC) of power, heat and transport sectors in this region are also becoming significant. Because of the presence of the national gas grids, the district heating networks, and other relevant variables, a well-researched strategy can make the energy transition happen successfully. Therefore, the NS region can be seen as a representative region that encompasses the key challenges for the energy transition, and tools and methods to solve these challenges is able to create an exemplary pathway for an overall global energy transition to combat climate change.

A number of research projects, for example, 'The North Sea Region Programme' by Interreg [9], Energy Systems in Transition (ENSYSTRA) [10], etc. are especially focused on the NS region with an aim to draft the exemplary pathway for the energy transition. This review paper is one of the outcomes of the EU Horizon 2020 project ENSYSTRA, which focuses on the enablers and consequences of the energy transition in the North Sea region. To envision the future energy transition pathways in the NS region, it is important to have a comprehensive understanding of the sector coupling practices, the potential uses, and benefits of sector coupling, state-of-the-art energy system models to accommodate sector coupling, and straightforward methods to select appropriate energy system tools. A clarified understanding of existing literature reviews can aid apprehending a legitimate research methodology, which will eventually constitute a pathway for performing further research to find out the optimum approach towards the desirable transition.

The coupling of different sectors in the energy system is expected to play a vital role to realize the energy transition in the NS region. Initial findings on the sector coupling modelling attempt in the ENSYSTRA project suggests that there is a knowledge gap in the comprehensive understanding of the relatively new term 'sector coupling' and the application of sector coupling in different energy modelling tools. Additionally, there is no straightforward method to select one or more tools from the broad range of available state-of-the-art energy models to portray a comprehensible picture of the energy transition over different temporal and spatial levels.

\subsection{Objective}

The general objective of the research can be formulated from the motivation, which is to provide a comprehensive understanding of sector coupling and how to incorporate sector coupling concepts in energy system models. To realize sector coupling in energy system models the following two research questions can be composed:

1. How can sector coupling be defined and realized from the far-reaching perspective of energy system modelling?

2. Which of the state-of-the-art tools are accessible to model sector-coupled energy systems, and how to choose an appropriate tool?

Based on these two questions, the general objective can be further interpreted as follows:

1. To understand the definition of sector coupling and its potential role and applicability in the energy transition.

2. To comprehend the progression of state-of-the-art energy system models, and selection of appropriate modelling tools based on the rationale of the research.

An additional sub-objective relevant to the research is to show the usefulness of an appropriate tool from the list of appropriate models. Hence the use of the open energy modelling framework, 'Oemof', as a potential tool has been corroborated in the latter part of the paper.

\subsection{Methodology}

The literature review of the paper is mainly divided into two parts. The first part reveals the literature in 'sector coupling' and the second part reveals the literature in 'energy system modelling'. 
Since there has been a significant evolution of research in different periods of time, both parts have been subdivided according to research performed in different decades. Google Scholar Database was screened for articles mentioning the following keywords-sector coupling, energy system modelling, North Sea energy, energy transition, $100 \%$ renewable, power-to-heat, and power-to-gas. The initial screening included journal articles from Energy, Energies, Applied Energy, Energy Policy, International Journal of Energy Research, International Journal of Hydrogen Energy, Applied Thermal Engineering, Renewable and Sustainable Energy Reviews, Sustainability, International Journal of Sustainable Energy Planning and Management, and Energy Economics. Additionally, a number of important articles and reports from different projects in the field of energy systems have been reviewed. Nevertheless, the paper does not claim to deliver a complete account of all published research on sector coupling and energy system modelling. Alternatively, the paper aims to present a broad account of important approaches and findings in sector coupling from the energy modelling perspective.

The rest of the paper is presented in five different sections. The first two sections (Sections 3 and 4) summarize the literature review on sector coupling and energy system modelling. The aim of Section 3 of the literature review is to investigate sector coupling practices for energy transition in energy systems (mostly large-scale), to find out which are the coupled sectors, what kind of methodologies have been applied to analyze these systems, renewable technologies that are present and most likely to be integrated in these systems, how the technologies have been used to handle the seasonal behavior of renewables, and the role of prominent energy storage technologies as well as the plausible evolution of the transport sector using electricity or hydrogen in a sector-coupled energy system. Although a number of $100 \%$ renewable-based systems has been mentioned in the literature review, the objective is not to analyze and review in detail all the 100\% RES-based systems, rather the objective is to understand the state-of-the-art of sector coupling and what role it is likely to play in the energy transition for renewable-based energy systems. The objective of Section 4 is to present the relevant review of the energy system models, followed by a list of the up to date energy system models that are open or free for academic use. The aim of Section 4 is not to look deep into all the pros and cons or to find the weak spots of existing energy system models. Instead, Section 4 tries to summarize the energy models and their reviews to have an overall understanding of the evolution, current state and the scope of the models.

Section 5 formulates the selection of appropriate tools based on the rationales of the research, which in this case is the selection of open source energy system models with the availability of all renewable generation components, energy storage, sector coupling options, suitability for various locations, scalability and grid modelling scopes. A short description of the selected tools along with their references are provided at the end of Section 5. In Section 6, 'Oemof' is presented as a potential tool based on the rationales of the selected list of tools. The core concept, features, examples, and the motivation for using Oemof are hence described in this part. In Section 7, a summary and a critical discussion based on the literature review has been presented. The final part concludes with the recommendations for future research in this field. Figure 4 presents a quick look at the methodology and the significant points of the review.

In summary, the rest of the paper is arranged as follows. Section 3 construes the literature review on sector coupling. Section 4 depicts a literature review on energy system modelling. Section 5 presents a methodology for an appropriate tool selection. Section 6 presents 'Oemof' as a useful open energy modelling tool. The lessons learned from the review and future recommendations for the upcoming research are discussed in Section 7. Appendix A demonstrates the complete list of open energy modelling tools adapted from various resources. Appendix B illustrates a detailed comparison between the selected modelling tools based on different parameters in 3 different tables. Appendix $C$ lists the elaborations of the acronyms used throughout the paper. 


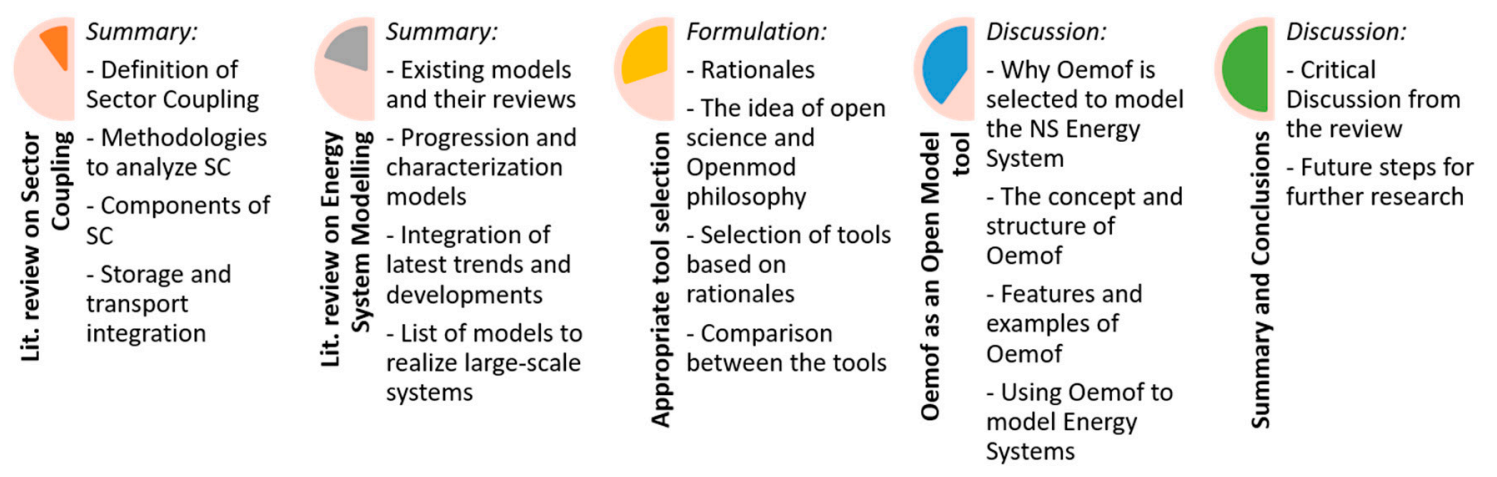

Figure 4. Research methodology.

\section{Literature Review on Sector Coupling}

To make the energy transition successful in the NS region all the major energy sectors (power, heat, transport, and industries) should focus on renewable energies. For example, heating systems can run by electric heat pumps or resistance heaters, or vehicles can be driven by electricity or bio-fuels. Integrating different sectors is often interpreted as 'sector coupling', which helps to incorporate more renewable energy sources. A more elaborate definition is discussed in the next section.

\subsection{Definition of Sector Coupling}

Sector coupling indicates the concept of combining different energy-consuming sectors-such as electricity with heating, cooling, transportation, etc. The integration of different sectors can provide flexibility and reliability to the system. For example, electricity can be used for district heating (power-to-heat, also known as P2H), or for producing hydrogen and synthetic gas (power-to-gas, also known as P2G). The gas can be stored, to either fuel vehicles, or to provide backup for electricity or heat conversion in peak times. Another example is the use of biofuels, which can stimulate the greenification heating and transport industries [11].

In the heating sector, $\mathrm{P} 2 \mathrm{H}$ technologies hold great opportunities for the energy transition. An important example is the heat pumps that use electricity to absorb existing heat from the Earth, to compact it and then to use it for the operation of the heating system. This is also efficient, for example in energy-efficient buildings, a good heat pump with a coefficient of performance $(\mathrm{CoP}) 3$ is able to produce $3 \mathrm{KWh}$ thermal energy by consuming $1 \mathrm{KWh}$ of electricity. However, it is necessary to mention here that $\mathrm{CoP} 3$ does not indicate the efficiency of $300 \%$, which is thermodynamically impossible, rather it indicates that $1 \mathrm{KWh}$ of electricity can be used to run the compressor and required pumps to transfer the energy from environmental heat sources to a building [12].

The transportation sector is another major consumer sector of electricity. It is possible to electrify the transport sector in many areas. For example, electric cars and trains are already in use in Europe in many countries. It is important to expand the charging infrastructure for the extended use of electricity in these areas. Overhead lines for heavy cars are also being tested. Besides electricity, hydrogen can be another option for making the transport sector more environmentally friendly. Electrolysis can be used for this P2G technology, which is a reversible process. Bio-fuel is another attractive fuel option in the transport sector because of their energy density, easy distribution system, adaptability with current motor engines [13].

The idea of sector coupling is visualized in Figure 5 which has been adapted from [14]. This figure illustrates only the major renewable energy resources and the three main energy sectors. Power-to-heat, power-to-gas or power-to-liquid (also known as P2L) are often referred to as power-to-X (P2X) as shown in Figure 5. It needs to be mentioned that the integration of different sectors can be more complex, and include more resources and sectors (for example, industries). 


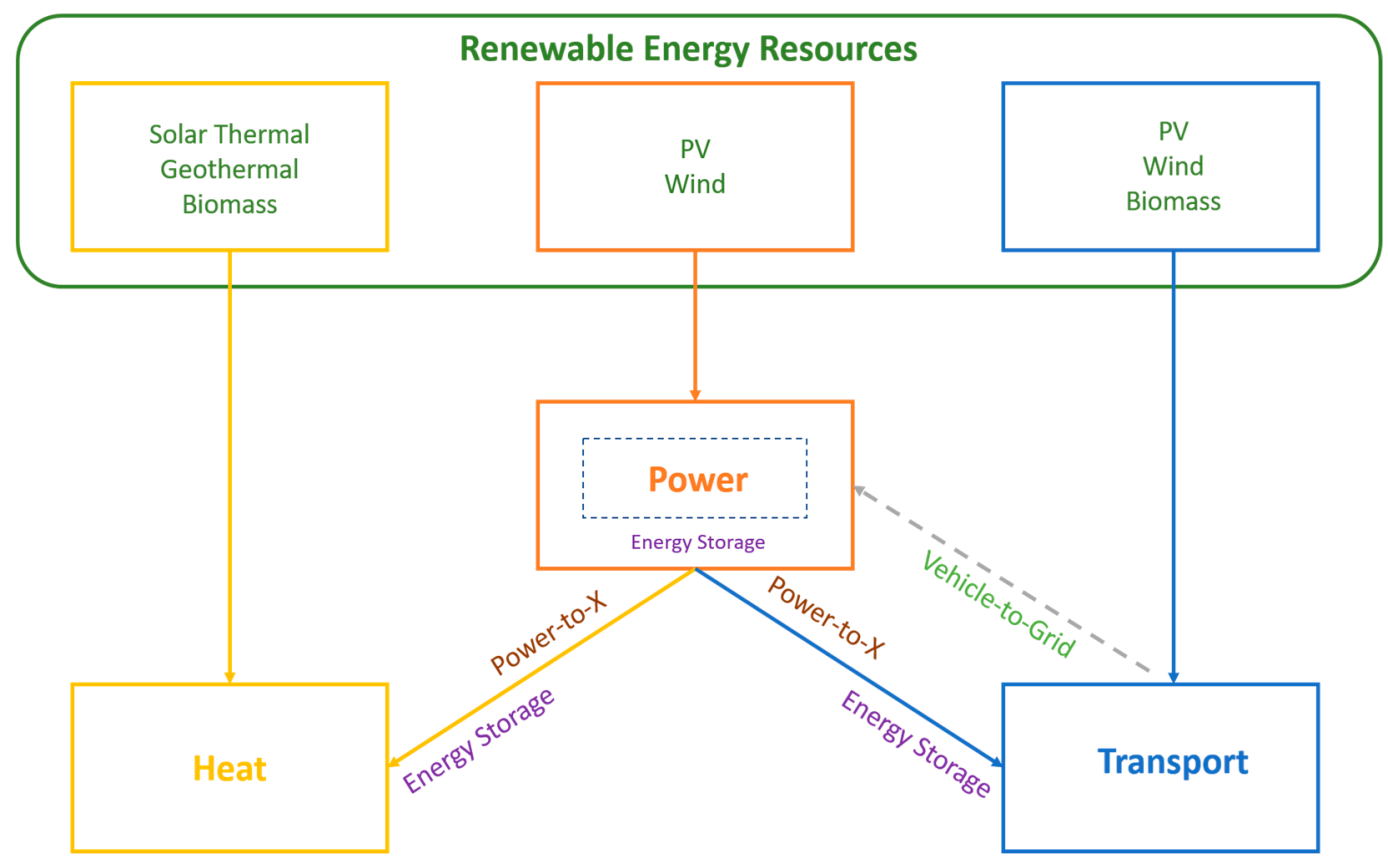

Figure 5. The idea of sector coupling between power, heat and transport sectors. Adapted from [14].

In the next two sections, relevant research on sector coupling, especially focusing on the national level is presented. While Section 3.2 focuses on research from 2001-2010, Section 3.3 focuses on more recent reviews, from 2011 to the present.

\subsection{Literature Review on Sector Coupling from 2001 to 2010}

Early research on sector coupling can be traced back to the short report of Lehmann on 'Energy Rich Japan' [15]. They used six different scenarios to exhibit how Japan can make a transition towards a renewable-based energy system using efficient energy technologies across residential, transport, industrial and commercial sectors. Later, the Danish perspective on sector coupling was demonstrated by Lund and his co-authors in several papers. For example, in one paper [16], Lund and Mathiesen presented the possibility for a $100 \%$ renewable-based energy supply in Denmark. They considered several alternatives such as wind, biomass, and hydrogen, and concluded that some of the energy carriers can also cause inefficiency in the design of the system, and this can be avoided if certain measures are taken beforehand. Lund et al. investigated the possible use of district heating and heat pumps in Denmark in another research work [17]. They recommended that the district heating networks in Denmark should be expanded from $46 \%$ to $63-70 \%$ along with individual heat pumps to provide the optimal solution in the future energy system. Additionally, the concept of including electric vehicles (EV) and vehicle-to-grid (V2G) was discussed by Lund and Kempton in [18], where they identified that including EV and V2G to the system allows the inclusion of more wind electricity without surplus production, and thus reduces the carbon emissions. Descriptive renewable-focused energy scenarios developed in quantitative and qualitative terms for Austria was suggested by Madlener et al. in [19].

In a few works of literature, the use of hydrogen has been considered as a feasible technique to aid sector coupling. For instance, Sørensen discussed having hydrogen as an alternative in sector-coupled electric and heat sectors and additionally projected that hydrogen can also be used to supply fuel for half of the German cars [20]. Similar research outcomes are also exhibited by Krajačić et al. in [21], who concluded that hydrogen is a secure and technically expedient energy supply. Kim and Moon revealed in their research that carbon-emission reduction and energy-efficiency gain is possible through the use of hydrogen in the energy system of Korea [22]. Energy demand management, biomass gasification, load shifting and transport sector electrification for New Zealand were suggested by Mason et al. 
in [23]. Different perspective literature on sector-coupled European energy systems is presented by Zervos et al. in [24], which sketches out a way forward for 2030 and 2050 especially focusing on the policy recommendations to overcome the non-technical obstacles of sector coupling in power, heating, cooling, and transportation sectors.

\subsection{Literature Review on Sector Coupling from 2011 to Present}

Significant research has been carried out on sector coupling of national energy systems during recent years. For example, in [25], Connolly et al. presented the 100\% renewable-based energy system for Ireland where he equipped the heating sector with district heating and heat pumps, and the transport sector with electricity, hydrogen, and biomass. In another research work, the planning of a $100 \%$ self-sufficient energy system using renewables for Croatia was presented by Krajačić et al. [26]. The Chinese energy system was analyzed by Liu, W. et al. [27], where they recommended changing the current infrastructure to match the power supply and demand with renewables. Ćosić and Krajačić proposed a 100\% renewable-based Macedonian energy system with a high share of solar, wind and biomass, along with various storage technologies [28]. Henning and Palzer modeled the sector-coupled future energy system for Germany consisting of electrical and heating and storage components and analyzed the system's cost and performance values [29]. In the second part of their research, they concluded that $100 \%$ renewable energy can feed the power and heat demands (space and hot water) of the entire building sector in Germany [30]. Electrification of the gas sector in Canada was examined by Garmisri et al. in [31], where they considered the plausible benefits of P2G, using excess power from the wind to generate hydrogen. In another research work relevant to the P2G method, Qadran et al. showed that the overall operating cost of Great Britain's power-gas network can be reduced by producing hydrogen from electricity [32]. Sector coupling of power, heat, and transport in the future UK energy system was also explored by Teng et al. using an advanced stochastic analytical framework [33]. Another prospective national sector coupling example is from Guandalini et al. who evaluated the remote future $P 2 G$ potential for Italy and concluded that excess energy recovered from renewables can be used for 7\% of Italy's current fuel consumption [34].

Delucchi and Jacobson analyzed the feasibility of integrating power, heat and transport sectors from $100 \%$ renewables all over the world and concluded that the barriers are not economic or technological, rather predominantly social and political [35]. In [36], Connolly and Mathiesen demonstrated that the techno-economic potential of renewable energy is dependent upon the availability of resources and fuel imports. They indicated that the transition needs to start soon, is plausible without any additional system costs, and can create a positive impact on local jobs. In other analogous research, Mathiesen et al. suggested that creating smart energy systems with smart infrastructures enables the proper utilization of flexibility components in a system, such as storage, heat pumps and EVs [37]. Mathiesen et al. presented smart energy systems integrating electricity, heat and gas grids to realize $100 \%$ RES. They presented the use of biomass in a limited and sustainable way and concluded that energy transition towards a bio-energy free sector-coupled system is possible via smart energy systems. An aggregated energy model was analyzed by Nastasi and Lo Basso., who considered P2G as a solver of dispatch issues relevant to the storage and energy market [38]. Another optimal design and operation of the wind-hydrogen-electricity network were presented by Samsatli et al. in [39]. The electrification of public transport with fast-charging batteries was investigated and determined by Rogge et al. [40].

In [41] Buttler and Spliethoff reviewed the role of water electrolysis coupling electricity, heat, transport and chemical sectors via P2G and P2L. An interesting revelation from their paper is that water electrolysis is likely to play an important role in providing flexibility to large energy storage applications. However, there is a need for more investigation and progressive optimization to integrate the electrolysis process in different sectors. Schaber presented an elaborated least-cost optimization energy model for Germany in [42]. The research compared sector coupling options and their economic impact with electric storage via two different scenarios. The research results suggest that long-term hydrogen or gas storage becomes debatable when the heat sector is electrified using renewables. 
The model also showed that in long-term scenarios, grid extension from North to South is necessary to electrify the heat sector in Southern Germany. They concluded that sector coupling with variable renewable energy integration can improve the economic efficiency of the German energy system. Gils et al. presented a $100 \%$ system for Brazil with sector coupling options and revealed that solar and wind can be more cost-effective than installing new hydro-electric plants [43]. Their model results indicate transition towards $100 \%$ system requires coupling of electricity, heat and transport sectors via $\mathrm{P} 2 \mathrm{H}, \mathrm{EV}$, and hydrogen options. The transition is also heavily dependent on local development, public perception, and industrial policies. Liu et al. discussed the concept of integrating the transport sector using different EVs and assessed the ability to include more fluctuating wind power in the energy system in Inner Mongolia in China [44]. They also recommended the inclusion of heat pumps and pumped storage in the energy system to enhance benefits. In another paper, Liu et al. recommended to mitigate individual transport demands, improve the efficiency of vehicles, and increase alternative fuels from renewables to provide a long term solution in China [45].

In [46], Mathiesen et al. concluded that 100\% RES-based systems can impact socio-economic actions positively while creating more job opportunities leading to extensive export incomes. They also revealed that in future the $100 \%$ systems will be competitive in comparison with the current systems, based on the challenges of climate change and economic development. The concept of adding smart thermal grids to implement fossil-fuel-free heat supply in future smart and sustainable energy systems was discussed by Lund et al. in [47]. The need for smart energy systems has also been explained in [48] where Lund et al. recommended that the integration of renewables in the power sector should be harmonized with the heat and transport sectors, with a focus on energy efficiency. In this paper, they also described the importance of combined heat and power (CHP) in providing flexibility for power supply-demand balance and stabilization of electrical grids. The idea of decarbonizing the heat sector via the use of district heating and heat pumps has been discussed in [49] by Connolly et al. in their Heat Roadmap Europe. Their heat strategy indicates a significant reduction in heating and cooling costs and recommends considering environmental pollution and policy impact parameters while integrating the transport sector in the future decarbonization approaches. In a similar strategic paper on Heat Roadmap China, Xiong et al. revealed the idea of district heating as a long-term solution to reduce dependency on fossil fuels and to decrease system costs [50]. David et al. discussed the role of large-scale heat pumps in future energy systems and concluded the replication of heat pumps throughout Europe is technically feasible [51].

Connolly et al. presented a pathway for a 100\% EU energy system by 2050 in 9 transitional steps in [52]. They concluded that the transition towards a $100 \%$ system in the EU depends more on politics and societal abilities rather than on cost-effective energy solutions. Electricity storage is not the optimal solution to integrate large inflows of fluctuating renewable energy since more efficient and cheaper options can be found by integrating the electricity sector with other parts of the energy system and by this creating a smart energy system. In [53], Lund et al. presented the idea of sector coupling in smart energy systems as a more efficient and cheaper option than integrating energy storage. However, they did not recommend to exclude energy storage from the system since they provide other usabilities in future energy systems. The feasibility of $100 \%$ RES-based systems was further validated in a recent paper by Brown et al., where the authors discussed demonstrated that $100 \%$ systems are not only feasible but also viable. The comprehensive list 100\% RES-based systems and their proven examples can be found in the paper by Brown et al., which covers the globe as well as its continents, sub-continents, countries, regions, and sub-regions [54]. A recent review of the concept of smart energy systems can be found in the paper by Lund et al. [55]. The term 'smart energy system' can be used to signify sectoral integration instead of considering individual sectors. According to Lund et al., the idea of smart systems can provide plausible efficient and achievable solutions. Another paper from Lund compares the concepts 'smart grids' with 'smart energy systems' and concludes that the latter (with sector coupling) can be implemented with relatively lower investments with a minimum extension of grids and storage facilities [56]. 
Some of the latest prominent researches on sector coupling in Europe can be found in the papers $[57,58]$ and [59]. In [57], Robinius et al. analyzed the potential of sector coupling and linked the electricity and transport sectors on national, continental and global levels. In the follow-up paper [58], they outlined an approach for the modelling, especially focusing on the power and transport sectors of Germany. The model results were presented by means of excess power, electrolysis application, hydrogen infrastructure, and economic analysis to show the potential benefits of sector coupling. Brown et al. considered two concepts in his renewable-based model, electrification of heating and transport sectors, and reinforcement of the inter-continental transmission network in Europe. Their scenarios concluded that, while the battery electric vehicles can balance solar power variation, P2G and thermal storages can balance long-term variations in supply and demand. They also concluded that the system cost can be reduced through the expansion of the transmission network, but only when the sectors are weakly coupled [59].

\section{Literature Review on Energy System Modelling}

In this section, an overview of energy system models and a list of appropriate open-source energy models have been presented, which can be helpful for the scientific community working on modelling large RES-based systems. Sections 4.1-4.3 sub-categorizes the energy modelling research into three periods.

\subsection{Reviews of Energy Models from 1970 to 2000}

The earliest review of energy models can be traced back to the research reports by Charpentier et al. in which they described 14 energy models and classified them in terms of substance and geographical applicability [60]. Beaujean et al. developed the first survey of global and international energy models based on earlier reviews by Charpentier et al. [61]. Meier in his book contrasted different energy models and proposed a categorization taxonomy for developing countries [62]. In [63], Markandya focused on power system planning models, with a focus on environmental concerns and developing countries. In [64], Grubb et al. classified energy models based on six dimensions: bottom-up and top-down, temporal horizon, sectoral scope, simulation and optimization, aggregation level and geographical scope. Energy models were also compared by Shukla in [65], where he evaluated the bottom-up and top-down approaches. Bhattacharyya undertook a comparison between equilibrium energy models in [66]. Using different energy models to reduce $\mathrm{CO}_{2}$ emissions in future European energy systems was presented by Krause in [67]. Hourcade and Robinson determined three objectives for energy system models: forecast, backcast and scenario development [68]. Kelly and Kolstad contrasted between the evaluation models for controlling climate change in [69]. The classification of energy models and how an energy model can be selected for regional planning was described in the book by Van Beeck [70].

\subsection{Reviews of Energy Models from 2001 to 2010}

Between 2001 and 2010, there were two elaborated energy model reviews. The first one was by Jebaraj and Iniyan in 2006, in which they reviewed a list of energy models including planning models, supply-demand models, forecast models, renewable models, emission reduction models, optimization models, neural network models, and fuzzy theory models [71]. Another detailed review was by Connolly, D. et al. in which the authors presented 68 different computer tools that can be useful to model renewable-based systems to meet various objectives needed for the energy transition [72]. Among other notable reviews, Pandey suggested incorporating the features of developing countries in energy-policy modelling and discussed the transition dynamics and barriers in [73]. Bahn et al. reviewed the modelling approaches for presenting, understanding and controlling the synergy between regional economies, their energy systems and their environmental impacts [74]. Nakata addressed different energy-economic model issues and application of the model in concurrence with renewable systems, national policies and environment [75]. Ventosa et al. focused on market modelling for electricity production to aid identification, classification, and characterization of approach divergence [76]. Urban et al. analyzed the performance of models dealing with developing country aspects [77]. 
Hiremath et al. explained why decentralized planning is needed for energy systems and how energy models can be accommodated in the decentralized level [78]. Sensfuß et al. reviewed agent-based models that can be used to investigate market power and designs [79]. Van Ruijven et al. discussed the compatibility of global energy models for developing countries in [80]. Möst et al. presented approaches via stochastic modelling for liberalized electricity markets in [81]. Foley et al. provided techniques for electricity modelling and examined a few USA- and Europe-based power system models [82]. A comparison of existing energy models was also discussed in [83], where Bhattacharyya and Timilsina investigated the suitability of models for analyzing energy, environment and climate change-related policies of the developing countries.

\subsection{Reviews of Energy Models from 2010 to Present}

There are significant pieces of literature on energy system modelling focusing on the latest trends and developments in the modern energy systems and looking forward to the energy transition. For example, in [84], Bazmi and Zahedi revealed the role of optimization modelling as a useful tool in the renewable-based energy systems. They also assessed the long-term potential of P2G, the foreseeable change in the demand pattern and penetration of photovoltaics (PV) and wind in a national energy system in their research. The key areas of urban energy systems were discussed by Keirstead et al. which are the design of technologies, building, and systems, urban climate, assessment of policies, use of land and modelling of transportation systems [85]. Energy economic optimization models were reviewed by DeCarolis et al. in [86]. They provided recommendations regarding a sustainable software framework for repeatable analysis and suggested that models should be open through cross-examination of open code and data, and everyone should be able to verify the model results by running the model using the open code and data. Energy demand forecasting models were reviewed by Suganthi and Samuel in [87], and the models are characterized by traditional and computational methods, support vector regression, ant colony, and particle swarm optimization, and bottom-up methods. Policy process models were presented by Hedenus et al. in [88].

While revealing the 21st-century challenges for energy system modelling, Pfenninger et al. divided the models into four categories: optimization models, simulation models, market models and qualitative and mixed-method scenarios [89]. According to their research, the four key challenges are the temporal and spatial resolution, the balance of transparency and uncertainty, recognizing the increasing complexity of energy systems and incorporating people's behavior, associated social risks and opportunities. An integrated model to evaluate the possibility of energy efficiency in the industries were analyzed by Olanrewaju and Jimoh in [90]. Li et al. introduced the term STET for socio-technical energy transition, and analyzed the STET models and their operation for three sectors: energy supply, transportation, and buildings [91]. The recent optimization techniques for hybrid (PV-wind) renewable energy systems were reviewed by Sinha and Chandel in [92]. A typology of long-term energy system and power system tools were abstracted by Després et al. in [93]. Multi-energy systems models on city level were summarized by Van Beuzekom who concluded that none of them provide practical grid feasibility perspectives [94]. A methodical approach to identify the established modelling tools via literature reviews and policy papers were presented by Hall and Buckley in [95]. Tools for modelling EVs and their characteristics were reviewed by Mahmud and Town in [96].

The latest developments in energy system modelling and their detailed overview can be found in the research papers by Sola et. al. [97], by Ringkjøb et al. [98] and by Lopion et al. [99]. While the perspective of Sola et al. was to implement the recent co-simulation methods for city-scale energy system models, Ringkjøb et al. presented an elaborate review of 75 recent energy system modelling tools which consider renewables as main generating resources. Lopion et al. [99] reviewed 24 national-level energy models which included all the energy sectors. A list of open energy modelling tools can also be found in [100], where a list of energy models published under open-source licenses are frequently added and updated by the Open Energy Modelling (Openmod) community. 


\section{Appropriate Tool Selection}

The 'Openmod Philosophy' is termed after the ideology of the Open Energy Modelling (Openmod) community, which demonstrates the idea of promoting open energy modelling, in which the source code is available freely for studies, modification, and improvement by the users. The 'Openmod Philosophy' is mainly aimed at increasing the transparency, reliability, reproducibility, and networking among the modelers and the users. It also avoids repetitive work and enhances education and public engagement. The energy modelling process according to the Openmod community can be illustrated as in Figure 6, which has been adapted from [101,102]. Details about the Openmod community can be found in [103]. The energy system transition towards carbon neutrality needs to perceive the idea of 'Openmod Philosophy' in energy system models now more than ever. The models need to be transparent, and openly accessible, to align with the policy relevance. The major steps to consider in the 'Openmod Philosophy' has been addressed by the Openmod community (Pfenninger et al.) in their research paper [102], where the authors discussed the strategies regarding code, data, intellectual property, license, modelling languages, supports, and community building.

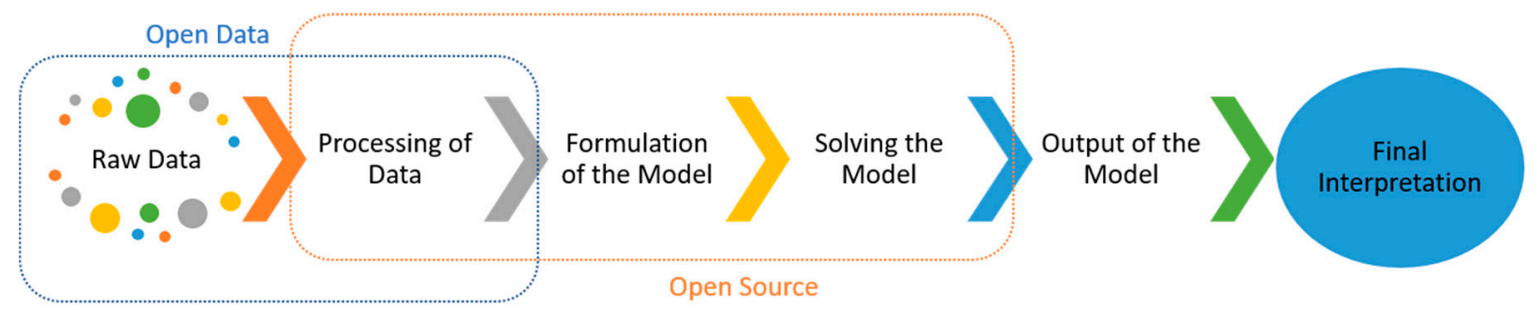

Figure 6. The process of energy modelling according to Openmod Philosophy. Adapted from [101,102].

\subsection{Rationale-Based Methodology for Selection of Tools}

Because of the eminent essentiality for open energy modelling required by the global energy system transition, the idea of 'Openmod Philosophy' has been considered as the key criterion in this research to select a number of tools to model an energy system. A primary list of recent energy system modelling tools (open and non-open) can be drafted by combining the 75 tools presented by Ringkjøb et al. [98], and recent open model tools listed by the Openmod community [100]. It is found that according to the 'Openmod Philosophy', the total number of tools narrows down to 59, which are open for energy modelling and at least free for academic use. The tools and their geographical resolutions can be found in Appendix A.

The list is then further shortened to accommodate the modelling of the sector-coupled renewable-based system. The rationale used further shortening the list is shown in Figure 7. The rationale used for shortening the list can be stated as follows:

1. The models follow 'Openmod Philosophy' of sharing code and data;

2. The model either provides all proven renewable components or the users have access to code to build and modify different components;

3. Energy storage is present or can be added to the model;

4. Realization and integration of different sectors (e.g., electricity, heat, and transport) are possible in the model;

5. The models can be replicated for any geographical contexts;

6. The model allows grid modelling;

7. The model horizon varies from sub-national to global levels to allow for modelling from different resolution aspects. 


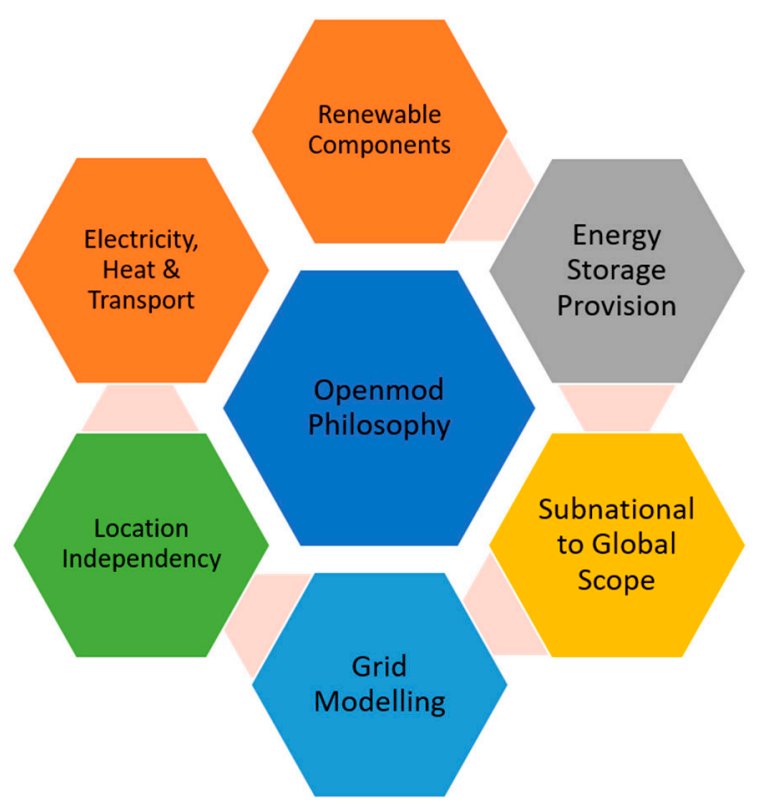

Figure 7. The rationales used for selecting tools to design a sector-coupled renewable energy sources (RES)-based system.

Hence the list then narrows down to 16 tools. It is necessary to be mentioned here that some of the omitted tools are capable of modelling sector-coupled RES-based system but with adjustment in regional data for renewable resources being used in the system. However, this paper focused on only the tools which fulfill all the designated criteria explicitly. Table 1 shows the shortlist of tools along with their methodology, temporal resolution, sectoral coverage (electricity, heat, and transport), and demand response consideration.

\subsection{Short Description of the Selected Tools}

This section provides a short description of the 16 tools which have been selected based on the rationales to design a sector-coupled RES-based system. Here it is necessary to mention that all of these models or modelling frameworks and their combinations are found to be suitable to fulfill the objectives of this research. The idea of open science and Openmod Philosophy is one important focus of this paper, which inspires the cross-use of open models and sharing the code and data. Modellers who want to develop a sector-coupled, RES-based system are encouraged to use any of these 16 tools, or any other tools based on the additional rationales of research, to portray different aspects of the energy system. A detailed comparison of the 16 tools can be found in Appendix B where the tools have been compared in terms of their objectives, approaches, geographical coverages, inclusion of conventional, renewable generation and storage, grid types, commodities, demand sectors, demand elasticity, costs, market modelling, emissions and software used for modelling. The tables in Appendix B have been adapted from Ringkjøb et al. [98], and open model tools [100].

\subsubsection{Calliope}

'Calliope' is an energy planning tool for systems ranging from districts to continents [104]. The main focus of calliope is flexibility, spatial and temporal resolution, and separate code-data platform. Pre-defined systems can be tested for different modes in calliope. Text files are used to define technologies, geographical location, and possible sources. The model then creates an optimization problem based on the files, provides a solution, writes the results in dataset formats so that they can be easily converted into Pandas structures. This helps a simple analysis using either endogenous Calliope or Python data-processing tools. 
Table 1. Proposed tools based on specific rationales for modelling sector-coupled and RES-based Systems.

\begin{tabular}{|c|c|c|c|c|c|}
\hline Serial & Tool & Methodology & $\begin{array}{c}\text { Temporal } \\
\text { Resolution }\end{array}$ & $\begin{array}{l}\text { Sectoral } \\
\text { Coverage }\end{array}$ & $\begin{array}{l}\text { Demand } \\
\text { Response }\end{array}$ \\
\hline 1 & Calliope & $\begin{array}{l}\text { Linear Programming } \\
\text { (LP) }\end{array}$ & User-defined & - & $\sqrt{ }$ \\
\hline 2 & $\begin{array}{c}\text { DESSTinEE } \\
\text { (Demand for Energy Services, Supply } \\
\text { and Transmission in Europe) }\end{array}$ & Simulation & Hourly & - & - \\
\hline 3 & $\begin{array}{l}\text { Dispa-SET } \\
\text { (Unit commitment and Dispatch } \\
\text { model. SET refers to the European } \\
\text { Strategic Energy Technology Plan) }\end{array}$ & $\begin{array}{l}\text { LP, Mixed-Integer } \\
\text { Linear Programming } \\
\text { (MILP) }\end{array}$ & Hourly & $\sqrt{ }$ & $\sqrt{ }$ \\
\hline 4 & $\begin{array}{c}\text { ELMOD } \\
\text { (Electricity Sector Model Family) }\end{array}$ & LP, MILP & Hourly & $\sqrt{ }$ & - \\
\hline 5 & ficus & MILP & 15 Minutes & $\sqrt{ }$ & - \\
\hline 6 & $\begin{array}{c}\text { LEAP } \\
\text { (Long-range Energy Alternatives } \\
\text { Planning) }\end{array}$ & $\begin{array}{l}\text { Simulation and } \\
\text { Optimization }\end{array}$ & Yearly & $\sqrt{ }$ & - \\
\hline 7 & $\begin{array}{c}\text { LUSYM } \\
\text { (Leuven University System } \\
\text { Modeling) }\end{array}$ & MILP & $\begin{array}{l}15 \text { Minutes, } \\
\text { Hourly, } \\
\text { Daily, } \\
\text { Weekly }\end{array}$ & - & $\sqrt{ }$ \\
\hline 8 & $\begin{array}{c}\text { MEDEAS } \\
\text { (Modelling the Energy Development } \\
\text { under Environmental and Social } \\
\text { Constraints) }\end{array}$ & Mixed & Yearly & $\sqrt{ }$ & - \\
\hline 9 & $\begin{array}{c}\text { Oemof } \\
\text { (Open Energy Modelling } \\
\text { Framework) } \\
\end{array}$ & $\begin{array}{l}\text { LP, MILP, Partial } \\
\text { Equilibrium }\end{array}$ & User-defined & $\sqrt{ }$ & $\sqrt{ }$ \\
\hline 10 & $\begin{array}{c}\text { OSeMOSYS } \\
\text { (Open Source Energy Modeling } \\
\text { System) }\end{array}$ & LP & User-defined & - & $\sqrt{ }$ \\
\hline 11 & $\begin{array}{c}\text { PowerGAMA } \\
\text { (Power Grid and Market Analysis) }\end{array}$ & Simulation, LP & Hourly & - & - \\
\hline 12 & $\begin{array}{c}\text { PyPSA } \\
\text { Python for Power System Analysis }\end{array}$ & LP & User-defined & $\sqrt{ }$ & $\sqrt{ }$ \\
\hline 13 & $\begin{array}{c}\text { RETScreen } \\
\text { (RET refers to Renewable-energy and } \\
\text { Energy-efficient Technologies) }\end{array}$ & Simulation & $\begin{array}{l}\text { Daily, } \\
\text { Monthly, } \\
\text { Yearly }\end{array}$ & - & - \\
\hline 14 & $\begin{array}{c}\text { SIREN } \\
\text { (SEN Integrated Renewable Energy } \\
\text { Network. SEN refers to the } \\
\text { Organization 'Sustainable Energy } \\
\text { Now Inc.') }\end{array}$ & Simulation & Hourly & - & - \\
\hline 15 & $\begin{array}{c}\text { SWITCH } \\
\text { (Solar, Wind, Transmission, } \\
\text { Conventional Generation and } \\
\text { Hydroelectricity) }\end{array}$ & MILP & Hourly & $\sqrt{ }$ & $\sqrt{ }$ \\
\hline 16 & $\begin{array}{c}\text { urbs } \\
\text { (Urban Energy Systems) }\end{array}$ & LP & User-defined & $\sqrt{ }$ & $\sqrt{ }$ \\
\hline
\end{tabular}

\subsubsection{DESSTinEE}

DESSTinEE is developed as a futuristic energy system model for the year 2050 in the European context [105]. The model is used mainly for testing electricity transmission assumptions and the economic obstacles that rise with the modelling. 40 countries have been included in the model with 10 primary- and secondary-energy forms. The technique used in the model is a predictive 
simulation. When the user provides data and assumptions into the model, it provides a set of answers as simulation results.

\subsubsection{Dispa-SET}

The Dispa-SET model is developed using the General Algebraic Modeling System (GAMS) and Python [106]. The model uses simple comma-separated values (CSV) files as input data. The methodology of the model is based on linear programming (LP) or mixed-integer linear programming (MILP) and depends on accuracy and complexity levels. There are two types of variables in the model. The continuous variables indicate power dispatch units, load shedding, and curtailed power generation. Binary variables indicate unit commitment status. The model solves the unit commitment problem by considering a central operator with full information. However, the unit commitment problem excludes optimal power flow calculations. The problem is subdivided into unit scheduling and economic dispatch problems. The goal of the unit commitment is to minimize the total system cost.

\subsubsection{ELMOD}

ELMOD consists of several spatial optimization models and demonstrates details of the European power sector including generation and transmission networks [107]. The modelling approach is bottom-up, and consider different engineering and economical parameters of the system. The models consider power flow in high-voltage grids as well as features of the generating units and results in minimum-cost or maximum-welfare dispatches. Market design, network congestion, and investment problems can be solved using ELMOD. ELMOD's several versions are ELMOD (for Europe), ELMOD-DE (for Germany), stELMOD (stochastic multi-market model), and dynELMOD (multi-period investment model).

\subsection{5. ficus}

'ficus' model is based on MILP and mainly used for expanding system capacities or solving unit commitment problems for local energy systems [108]. The model was originally developed for factories. If a demand time series is provided, the model finds the least-cost solution for commodities like electricity and heat. The model considers cost time-series, peak demand charges, etc. for every commodity. The model can be converted into an LP model by deselecting equations. The model is able to deal with multiple numbers of inputs and outputs for energy conversion and considers relevant efficiencies.

\subsubsection{LEAP}

LEAP is a popular scenario-based modelling tool that includes energy generation, consumption and all the economic sectors [109]. GHG emissions can be tracked for all the sectors. LEAP can analyze air pollutants and climate pollutants leading to local pollution reduction. Although LEAP does not represent a particular energy system, it can be used to develop different energy system models with unique data structures. A broad range of modelling techniques can be supported by LEAP including top-down and bottom-up modelling. There are also special methods to realize transport planning. LEAP provides both simulation and optimization techniques to model power sectors and capacity expansions. The models are transparent, flexible, and adaptable to other models.

\subsubsection{LUSYM}

LUSYM is an MILP-based unit commitment model developed by the University of Leuven (KU Leuven) [110]. It selects the optimized scheduling from a number of power plants to satisfy the electrical demand and takes into account all the operational parameters of the system. The mathematical formulations include power station limitations, load flexibility, curtailment of RES, storage options, grid parameters and limitations, spinning reserves, and must-run scenarios. LUSYM can be used for 
large-scale systems within reasonable simulation times. Through compact formulation, efficient data handling, and MILP solvers, the simulation times are reduced in LUSYM.

\subsubsection{MEDEAS}

The objective of MEDEAS is to develop a model to structure the futuristic energy system in Europe while considering the technical and social constraints [111]. The renewable-based transition in Europe and the required policies can be tested using the MEDEAS model. It considers various other tools, for example, WoLim (World Limits Model), TIMES (The Integrated MARKAL-EFOM System) and LEAP. MEDEAS considers input-output analysis to realize the socio-economic and environmental impacts. The design is modular, so that the system is flexible, and engages stakeholders from different categories. The model also provides high spatio-temporal resolution and involvement of sectors.

\subsubsection{Oemof}

Oemof is a framework for developing energy system models and different applications to perform energy system analysis [112-114]. The model generator of Oemof can be used for solving investment, dispatch optimization, and unit commitment problems. Oemof provides a detailed component-based modelling using mathematical formulation and includes heat components such as CHP, heat pump, heat storage, etc. The grids can be modelled via two approaches, either by trans-shipment or by linear optimal power flow. Oemof is being used as a modelling tool in several projects including ENSYSTRA [10], and hence the tool is described in detail in Section 6 of this paper.

\subsubsection{OSeMOSYS}

The OSeMOSYS tool is designed to assess long-term energy planning scenarios on different geographical scales (from continents to villages) [115]. The tool is ready to use by scientists as well as policymakers for its rapid learning curve and minimum run-time requirement. The tool balances energy supply and demand and minimizes the total cost. The tool includes sectoral integration as well as operating in different spatio-temporal levels. The energy resource component details incorporate technical and economic parameters, technology potentials and system costs. Real issues like techno-economic constraints or emissions can be addressed via policy scenarios. The tool is a deterministic, LP, long-term modelling framework, which is also adaptable to MILP for including complex functions.

\subsubsection{PowerGAMA}

PowerGAMA is a simple simulation tool for analyzing RES integration in large-scale power systems [116]. The tool is based on Python and provides high-level analysis for a dispatchable generation. The optimization is based on marginal costs for user-given timesteps. The tool considers the variability of RES and demand. Another important feature of PowerGAMA is that it considers alternating current (AC) grid power flows based on physical equations. PowerGAMA can address the flexibility assessment via storage inclusion, optimum energy mix, associated costs, and network congestion problems.

\subsubsection{PyPSA}

PyPSA is a tool for the simulation and optimization of modern power systems [117]. The tool considers various features, for example, conventional generation with unit commitment, variable renewable generation, storage inclusion, sector coupling, and mixed AC-direct current (DC) networks. PyPSA can be used for large-scale networks with a long time series. It can solve static and linear optimal power flow, least-cost optimization problems. The static power flows can be calculated using linear and nonlinear equations. Linear optimal power flow addresses minimum cost optimization of power and storage dispatching units using linear equations. Additionally, security-constrained linear 
optimal power flow can also be performed. The total system cost optimization can be undertaken using linear equations for optimizing generation and storage unit dispatch and considers investment in generation, transmission, storage, and other infrastructural capacities.

\subsubsection{RETScreen}

RETScreen is a popular pre-feasibility analysis tool for renewable energy projects [118]. It can be used for energy efficiency, renewable integration, and cogeneration for addressing the feasibility of an upcoming or ongoing project. There are two different versions of RETScreen, excel-based and graphical user interface-based (RETScreen Expert). The tool is easy to use and can be used by scientists as well as policymakers to determine, evaluate and optimize the techno-economic feasibility of clean energy projects. The tool also allows us to measure and verify the performance of an energy project and helps to determine the plausible savings opportunities. The tool is available in 36 languages, which enhanced the versatile use of the tool. Both conventional and renewable technologies are incorporated in RETScreen, which includes their efficiencies, sectoral integration, etc. The tool can be connected to the central databases for obtaining different input parameters. A number of available projects also simplifies the understanding of RETScreen based clean energy projects and their implementation strategies.

\subsubsection{SIREN}

SIREN is a toolkit that uses the 'System Advisor Model (SAM)' for energy calculations [119]. SIREN provides scenario building provisions for preferred energy mix. To build a scenario, a map can be chosen which addresses the current local electrical network in the map and allows additional stations by the user. The user can also obtain relevant data from other resources to put into the model. The result from the model is listed as shortfalls and is uploadable into the power balance component of the SIREN toolkit. This way, the cost of dispatchable generation, storage and emissions can be quantified. The final outcome is a complete RES-based scenario reflecting the costs.

\subsubsection{SWITCH}

SWITCH can be used for energy transition planning to modern energy systems to satisfy state-of-the-art grid requirements [120]. Investment and operational planning including renewable integration can be performed using this tool. There are several applications of SWITCH, such as resource planning via integration, fundamental research, techno-economic analysis, policy evaluation, etc. The electrical elements of SWITCH consider unit commitment, efficiency, supply curves, planning and operational reserves, storage provisions, demand response activities, hydropower networks, and policy limitations. The flexible architecture of SWITCH allows a user to choose reference models as well as write own customized models.

\subsubsection{6. urbs}

The model 'urbs' consists of various model entities [121]. The entities are commodities, processes, transmission, and storage. Intermittent supply and demand datasets can be modelled in urbs using time series. This model can generate linear optimization models for energy systems. The tool uses linear programming and can be used for capacity-expansion planning and solving unit commitment problems in distributed systems. The model can be adapted for varying geographical scales, from continental to local levels. The tool focuses on the optimized sizing of storages and their usage. It looks for the cost-optimal solution for the given time series for multiple commodities. the model generally considers hourly time steps and incorporates reporting and plotting features.

\section{Oemof as an Open Model Tool}

The literature review in Section 4 demonstrates that most of the energy system model reviews provide a general overview of the tools and the models are often classified based on their functionalities. 
However, the current modelling challenges and research questions are not addressed in most of the reviews. This research paper helps us to gain an idea of the model evolution, current challenges, and the available tools for energy system modelling. Section 5 carries on the idea of finding a suitable model for a specific purpose and hints on how based on several rationales of the specific purpose a model can be selected. This list of 16 tools does not predicate a 'must choose from' obligation, rather it helps a user to realize and justify which of the tools are suitable for a sector-coupled RES-based system open modelling. Hence, a user can select any of the 16 tools as described in Section 5, combine them, and even select an additional tool that is not in the list of Table 1. However, a short glimpse into the models with references is presented in the last part of Section 5 to have a fundamental idea about the tools. Followed by the short description, this Section (Section 6) discusses in detail one of the 16 tools 'Oemof' as one of the progressive tools. The reason for detailing this particular modelling framework is because this model will be used by the author in the next stages of modelling of the NS energy system as a part of the ENSYSTRA project [10]. However, readers are recommended to go through the references [104-121] and to have a detailed idea of all the modelling tools, so that they can choose the tools based on their specific research rationales.

Energy system modelling challenges are increasing with the growing complexities of the largely renewable-based energy systems and their high unpredictability. The challenges become more complex when they incorporate issues like integration of variable renewable energy sources [122], forecasting methods [123], demand-response mechanisms [124], power-handling capabilities [125,126], etc. in the model. In the research paper by Hilpert et al., the authors addressed the key challenges of energy system modelling which include complexities, uncertainties, interdisciplinary modelling, scientific standards, and model utilization [127]. They introduced the concept of the modelling framework Oemof as a contemporary approach for modelling energy systems and explained how Oemof can be used to tackle the challenges of modern energy systems.

\subsection{Why Oemof Can Be Used as A Tool to Model the North Sea (NS) Energy System}

Oemof can have a significant contribution in open science through the use of its free and open-source software, collaborative development and modular structural representation. The challenges as mentioned in [127] can be addressed by Oemof's open philosophy. Some of the significant features of Oemof to address the energy system modelling challenges are:

1. Oemof is able to create flexible energy system models due to its easily integrable generic structures and object-oriented approach.

2. Oemof addresses the uncertainty through the use of collaborative modelling to look deep into various decisive features of energy systems.

3. Oemof allows interdisciplinary modelling to understand common research problems in energy systems.

4. Oemof follows strict scientific standards via different levels of control mechanism to ensure transparency and reliability. Oemof also allows repeatability, reproducibility, and scrutiny of the model.

5. The open-source, open data approach of Oemof also allows communication between modellers policymakers and other stakeholders, which enhances the understanding of energy systems and accelerates the energy transition.

An investigation into the details of Oemof [112-114] and its applications and usage [128-137] suggest that it has the ability to include all the conventional and renewable generations of the NS energy system. It is clear from the analysis of the aforementioned references that most of the proven components of an energy system are already available in the Oemof framework. In addition, Oemof provides provisions to include different kinds of storages and dispatchable loads. The Oemof framework has cross-sectoral modelling opportunities including heat and transport. Because of its 
suitability to model the NS energy system, the next two sections discuss the core concept of Oemof, its features, components, and the plausibility of using Oemof for modelling a large-scale energy system.

\subsection{The Concept of Oemof}

The acronym Oemof is derived from 'Open Energy Modelling Framework'. Oemof provides an energy modelling toolbox that is open-source, free and has very good documentation [112-114]. Python is its base language, and it has a modular structure with various packages which are linked via explicit interfaces. In Oemof, the energy system is represented by a network of 'nodes' which are connected via 'flows'. 'Nodes' represent either balance spaces or entities of an energy system and 'flows' represent energy flows. 'Buses' and 'components' are two types of nodes. While buses are used to connect the components (e.g., electricity bus, heat bus), the components indicate generators and consumers in the energy system (e.g., power plants, storage units, loads). Flows are used to represent the inputs-outputs of components (e.g., electricity, heat). There are basic components present in the Oemof framework, which can be used directly or can be modified according to needs. The main concepts of the theoretical formulation of Oemof can be found in the research paper by Wingenbach et al. [138].

A simple energy system can be presented in Oemof as a combination of source and sink components, and transformers. The 'source' indicates the producing component (e.g., wind turbine) and the 'sink' indicates the consuming component (e.g., loads). The 'transformer' indicates the producing and consuming component to and from different buses (e.g., gas-fired power plant). Figure 8 presents a simple energy system in Oemof illustrating its components and buses.

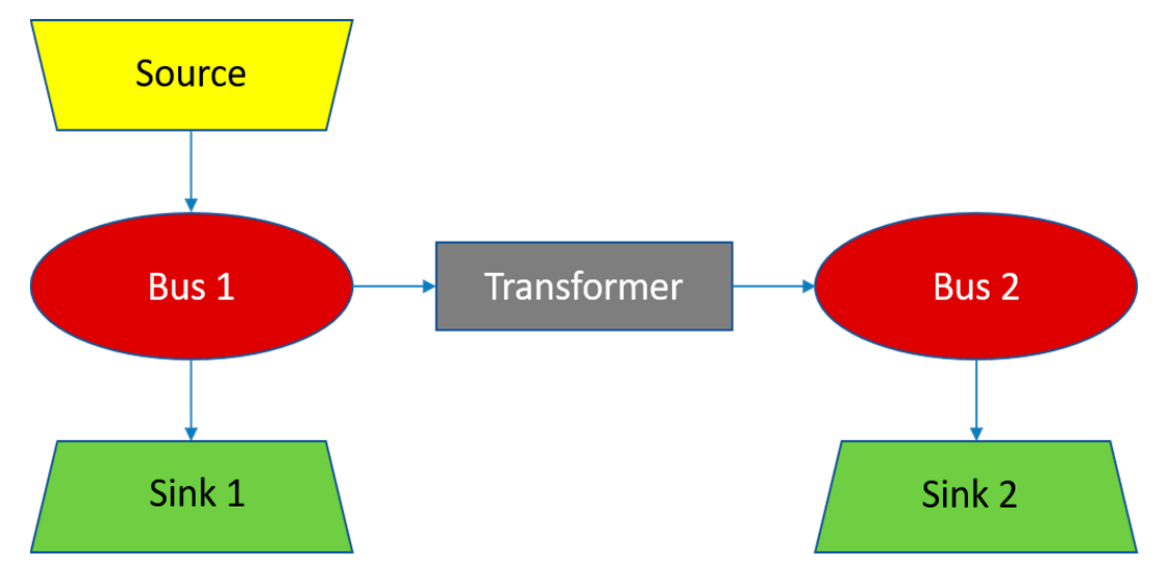

Figure 8. Illustration of a simple (Open Energy Modelling Framework) Oemof energy system. Adapted from Oemof Documentation [114].

\subsection{Using Oemof to Model Energy Systems}

Oemof libraries can be combined to write an application to model an energy system. The current Oemof libraries are- network, solph, outputlib, feedinlib, and demandlib. In Oemof network, the components (sources, sink, and transformer) are required to be connected to one or more buses. The solph library can solve optimization problems like LP and MILP. The energy system also has additional components such as storage. The outputlib collects the results of optimization, which can be visualized using any plotting library. Feedinlib and demandlib can be installed additionally to calculate feeding time series and load profiles.

In an Oemof-network, a source has one output. For example, energy-generating sources like solar PV plants, wind turbines can be considered as sources. Similarly, a sink has one input. Electricity and heat loads in a household can be represented by a sink. Transformers have multiple inputs and outputs. For example, a combined heat and power (CHP) plant can get gas from the gas bus and provide electricity and heat demand via the respective buses. Transformers can also be used to model transmission lines in the energy system. 
Figure 9 shows another example of an Oemof-network-based energy system where PV, Wind and a Gas plant are used as sources, a CHP is used representing a transformer, a storage component is connected to the electricity bus, and electricity and heat loads are representing sink components. There are three buses in the energy system, namely electricity, heat and gas bus.

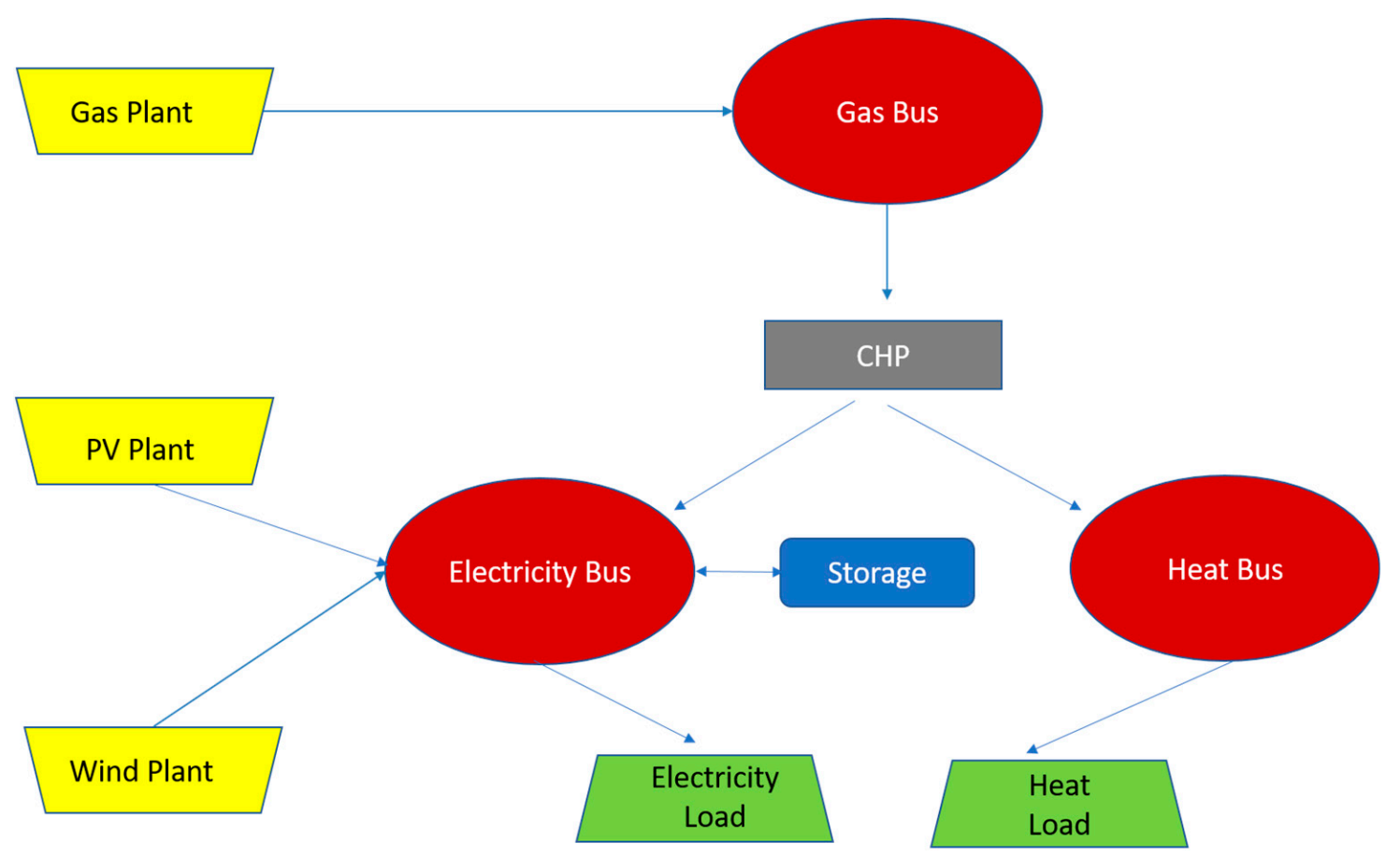

Figure 9. Exemplary energy system showing Oemof-network components. (Author's illustration).

To create an Oemof application, at first, an empty energy system object is constructed which contains the nodes and sustains information. Different scenario provision and node-handling capabilities are also provided in this step. The next step involves the population of the energy system nodes and flows. After that, the model is optimized using a solver. The final results are then processed using the output library in the last step. The usage can be separate or within one single model. A developer of Oemof can easily switch between economic dispatch, unit commitment, and investment modes by making minor changes depending upon the application developed.

Examples of Oemof usage can be found in multiple projects [128-133]. 'Renpass' [134], 'appBBB' [135], and 'Hesysopt' $[136,137]$ are some examples of Oemof applications which are used either to simulate future energy systems (renpass), or regional heat and electricity systems (appBBB), or support district heating system flexibilization (Hesysopt). These examples also prove the credibility of using Oemof for large and complex sector-coupled energy systems. An example of such a system modelled as an Oemof application is illustrated in Figure 10 which has been adapted from Hilpert et al. [127]. 


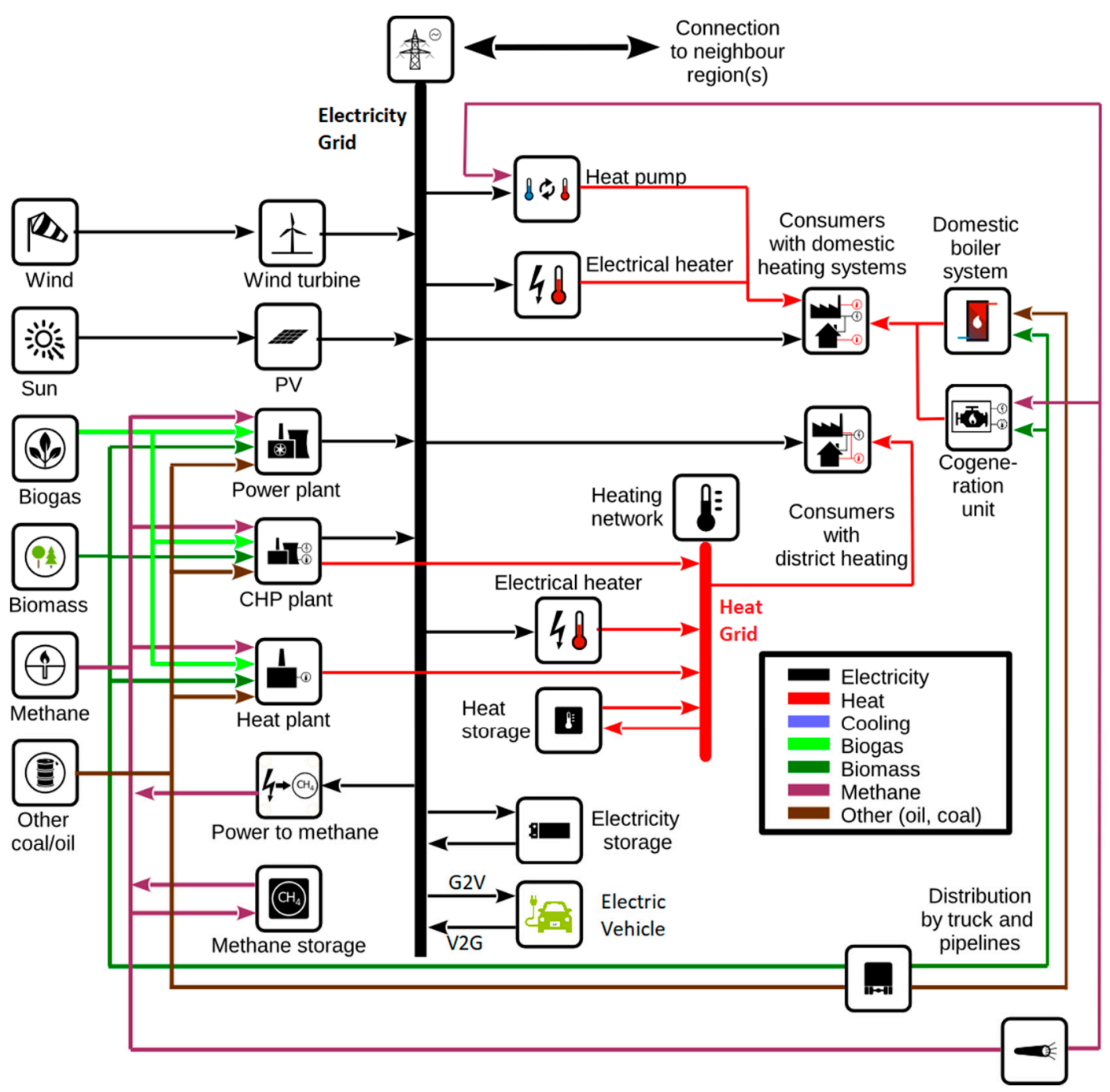

Figure 10. Exemplary sector-coupled energy system using Oemof. Adapted from [127].

\section{Summary and Conclusions}

\subsection{Lessons Learned}

To understand the role of sector coupling in the global context, the definition of sector coupling was delineated which was followed by the basic idea of integrating the heat and transport sectors into the power sector, the hypothesis of P2H, P2G, P2L and P2X required by the sectoral integration. The literature review on sector coupling was divided into two different timelines. The first timeline (2001-2010) presents national schemes for potential pathways towards a sector-coupled with future energy society and includes research examples from Japan, Denmark, Austria, Germany, Korea, and New Zealand. The second timeline (2011-present) presents the more recent trends in sector coupling and demonstrates examples from Ireland, Brazil, Mongolia, Croatia, China, Macedonia, Germany, Canada, Great Britain, UK, and Italy. Both of the timelines include the potential of various renewable resources, district heating, heat pumps, power-to- $X$, and hydrogen. Additionally, issues like the usage of smart grids, electrification of all the sectors, and optimal operation of the sector-coupled network are also key factors of the prominent research into sector coupling.

The evaluation of the different literature reviews for sector coupling has shown that there is a lack of a uniform view in science and politics and there is a definite need for a clear understanding. While some works of literature discuss only the transformation of renewable electricity to heat, gases or liquids, other works of literature also reveal about integrating all the aspects of energy sectors. Hence, 
a unique understanding of sector coupling can refer to the progressive process of substitution of fossil fuels through the use of known cross-sectoral applications using renewable resources. While electricity can be generated directly from renewables, heating, cooling, and transportation are possible via P2H, P2G, P2L, and P2X. Sector coupling does not only refer to supply-demand relations but also considers the interlinkage between the consumption sectors like households, commerce, trade, services, industries, transports, etc. While the main objective of sector coupling is to reduce GHG emissions by substituting fossil fuels, the secondary objective is to provide flexibility, network optimization and increased efficiency to the energy systems. The review summarizes that all the pathways have their pros and cons depending on their own geographical contexts, and solving the technical, economic, social and political challenges of sector coupling with regional attention is capable of sketching out a route for the required energy transition.

To understand the evolution, availability, and capabilities of energy system models, the literature review on energy system models is divided into three different timelines. The first timeline (1970-2000) presents the early energy modelling tools and their classification approaches. It is revealed from the review that some of the old modelling tools addressed carbon emission reduction, and some of the models were modified at a later stage to cope up with the transition in the energy systems. The second timeline (2001-2010) gives more attention to the use of renewable energy required by the energy transition, and also addressed other important issues in energy modelling such as national policies, environment, electricity market, regional economies, decentralized planning, etc. In the third timeline (2011-present), the idea of sector coupling has been taken into consideration by many of the models. The latest trends in energy modelling also include the concepts of power-to- $X$, electric vehicles, open science; and addresses challenges such as temporal and spatial resolution, the increasing complexity of the energy systems, societal barriers, etc.

One of the conclusions from the literature review of energy system modelling is, there is a shortcoming in the purposeful and efficient combination of different modelling approaches and viewpoints, as well as collaboration between modelling tools on various aggregation and spatial levels. The collaboration of different tools and ideas is necessary to provide a comprehensible picture of the necessary transition process of large-scale energy systems like the NS region. The combination of these tools will be able to translate techno-economic, social and environmental aspects of various strategies and scenarios. Another conclusion concerns the resolution aspects of energy system modelling. For example, when modelling from a national point of view, the aggregated models only provide more holistic pictures but are unable to portray regional or sub-regional specifics, which results in meaningless results at lower spatial scales including demand response. Hence it is very important to address the energy system modelling from smaller to larger spatial levels, in which different aspects of the energy systems, for example, technology components and their deployment potential, infrastructure, demand response, the participation of society, market behavior, costs, etc. are more specific and influential. Both of the spectrums, local and global, and the linkages between them are important to address the challenges of energy system modelling.

The next obvious question is, what is already there on the table, and how to choose one or many tools from this broad range of tools. The answer is, that selection of an appropriate tool can be based on the rationale of a project. For example, one key objective of this particular research project is to model an open-data, open-source, 100\% RES-system, with sector coupling options for electricity, heat, and transport. Hence based on these rationales, an example of shortening the list is presented in the last part of Section 3, where a list of 59 open energy modelling tools is shortened to a number of 16 tools. It can be presumed that most sub-regional to large scale challenges of the energy system transition and sector coupling can be assessed using a combination of these 16 tools. A detailed comparison between the 16 tools can be found in Appendix B. However, it should be noted that the collaboration of models for modelling a sector-coupled energy system is not only limited to these tools only. This list functions as an elemental reference based on the rationales, but other tools which are not present in this list can also coact together in order to portray different specifics of an energy system from different contexts. 
An additional realization from the literature review is that there is a need to include social and political aspects of the energy system models. The energy system modellers should not focus on least-cost optimization only, rather they should try to look for near-optimal solutions which include political and social processes. For example, the establishment of a new wind-power plant or transmission line may be accepted, actively taken up or resisted by the local citizens and these issues should be dealt with from social or political perspectives. Hence, the collaboration of modelling tools needs to take into account the insights of policies and investment planning to finalize the strategies for a smooth energy transition.

One of the promising tools to address the modern energy system challenges is Oemof, which is becoming widely popular and is capable of understanding complex energy systems. Therefore, the concept of Oemof is presented in Section 6, which is followed by the hypothesis behind Oemof tool, its core structure and components, and the usage of Oemof to design simple to complex energy systems. Based on the basic understandings of the Oemof model, it is speculated from the analysis that Oemof can be used as one of the advantageous tools to design the sector-coupled and $100 \%$ RES-based future energy system for the NS region.

\subsection{Future Steps}

This paper paves the pathway towards modelling of a sector-coupled system to facilitate the energy transition in the NS region. The literature reviews are intended to create a comprehensive understanding of sector coupling concepts and energy modelling. The paper also presents the selection of a list of appropriate tools based on the rationale and recommends the use of Oemof and similar open-model tools for modelling sector-coupled RES-based energy systems.

In the immediate next phase of the research, it is recommended to propose a detailed methodology for modelling the NS energy system, the architecture of the model, and the final analysis of the results from the model. The modelling should address the identification of input and output parameters, data handling, scenario planning, and regional applications. In the later phase of the research, it is also recommended that the model (or models) is (are) further validated through comparison and collaboration between different models. This way the errors can be further minimized and the models can be realized in close proximity to the real-world energy systems. In the final phase, it is recommended to analyze the impacts of sector coupling, storage and dispatchable loads in the energy system to find the optimal or near-optimal solution to craft the pathway and final recommendations required by the energy transition.

Funding: This research is a part of the ENSYSTRA project which received funding from the European Union's Horizon 2020 research and innovation programme under the Marie Skłodowska-Curie grant agreement No: 765515.

Acknowledgments: This work was supported by the ENSYSTRA network and by the Center for Sustainable Energy Systems (ZNES) by Europa-Universität Flensburg and the Flensburg University of Applied Sciences. The author would like to thank the Openmod Community and Oemof developers for spreading the idea of open-data and open-science in energy system modelling. The author is thankful to Christian Fleischer and Abhinav Bhaskar for their review, comments, and suggestions on the paper. Furthermore, the author acknowledges the support from Prof. Dr. Olav Hohmeyer, Prof. Dr. Bernd Möller, and Simon Hilpert for the guidance and cooperation throughout the project.

Conflicts of Interest: The author declares no conflict of interest. 


\section{Appendix A}

Table A1. Open energy modelling tools. Adapted from [98] and [100].

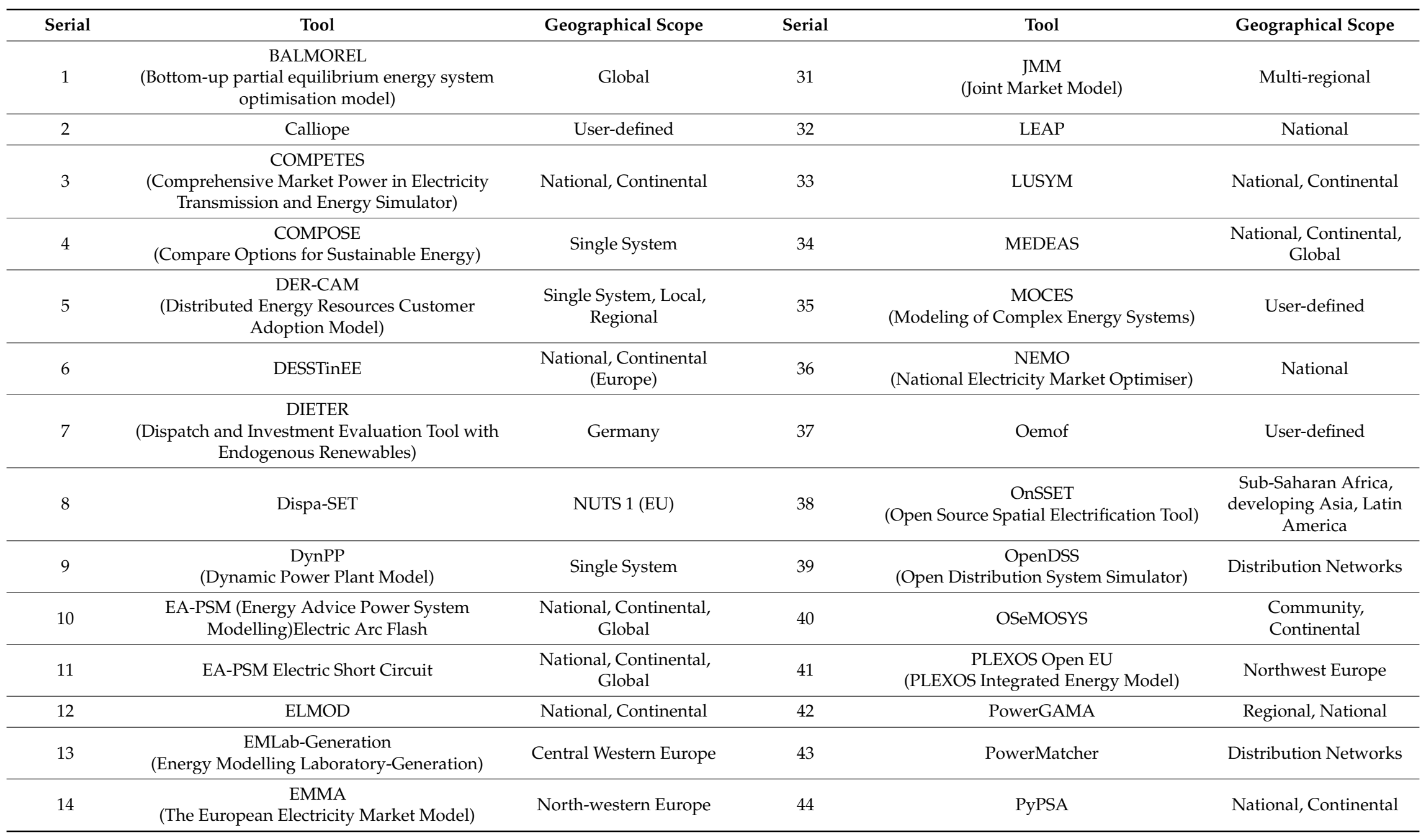


Table A1. Cont.

\begin{tabular}{|c|c|c|c|c|c|}
\hline Serial & Tool & Geographical Scope & Serial & Tool & Geographical Scope \\
\hline 15 & $\begin{array}{c}\text { EMPIRE } \\
\text { (European Model for Power system Investment } \\
\text { with Renewable Energy) }\end{array}$ & Continental (Europe) & 45 & $\begin{array}{c}\text { RAPSim } \\
\text { (Renewable Alternative Powersystems Simulation) }\end{array}$ & Local \\
\hline 16 & Energy Numbers-Balancing & National & 46 & Region4FLEX & Germany \\
\hline 17 & EnergyPlan & Local, National & 47 & $\begin{array}{c}\text { renpass } \\
\text { (Renewable Energy Pathways Simulation System) }\end{array}$ & Regional, National \\
\hline 18 & $\begin{array}{c}\text { EnergyRt } \\
\text { (Energy systems modeling R-toolbox) }\end{array}$ & Multi-regional & 48 & RETScreen & All \\
\hline 19 & $\begin{array}{c}\text { ESO-X } \\
\text { ESO refers to Electricity Systems Optimisation } \\
\text { (ESO) framework }\end{array}$ & Single node & 49 & $\begin{array}{c}\text { SAM } \\
\text { (System Advisor Model) }\end{array}$ & Single System \\
\hline 20 & $\begin{array}{c}\text { ETM (1) } \\
\text { (EUROfusion Times Model) }\end{array}$ & Global (17 Regions) & 50 & $\begin{array}{c}\text { SciGRID } \\
\text { (Open Source Model of European Energy Networks) }\end{array}$ & $\begin{array}{l}\text { Europe and Germany } \\
\text { (any other EU country } \\
\text { also possible) }\end{array}$ \\
\hline 21 & $\begin{array}{c}\text { ETM (2) } \\
\text { (Energy Transition Model) }\end{array}$ & Community - International & 51 & $\begin{array}{c}\text { SimSES } \\
\text { (Simulation of stationary energy storage systems) }\end{array}$ & Global \\
\hline 22 & $\begin{array}{c}\text { ETSAP-TIAM } \\
\text { (The TIMES Integrated Assessment Model) }\end{array}$ & Global (15 Regions) & 52 & SIREN & Regional, National \\
\hline 23 & ficus & Local, National & 53 & $\begin{array}{c}\text { SNOW } \\
\text { (Statistics Norway's World Model) }\end{array}$ & National, Global \\
\hline 24 & $\begin{array}{c}\text { GAMAMOD } \\
\text { (The Gas Market Model) }\end{array}$ & Europe & 54 & stELMOD & National, Continental \\
\hline 25 & $\begin{array}{c}\text { GCAM } \\
\text { (Global Change Assessment Model) }\end{array}$ & Global & 55 & SWITCH & Regional, National \\
\hline 26 & $\begin{array}{c}\text { GENESYS } \\
\text { (Genetic Optimization of a European Energy } \\
\text { Supply System) }\end{array}$ & EU-MENA (21 Regions) & 56 & $\begin{array}{c}\text { TIMES Évora } \\
\text { (TIMES refers to The Integrated MARKAL-EFOM } \\
\text { System) }\end{array}$ & Évora (Portugal) \\
\hline 27 & GridCal & Transmission Networks & 57 & TIMES-PT & Portugal \\
\hline 28 & GridLAB-D & Local, National & 58 & $\begin{array}{c}\text { Temoa } \\
\text { (Tools for Energy Model Optimization and Analysis) }\end{array}$ & US \\
\hline 29 & $\begin{array}{c}\text { iHOGA } \\
\text { (Improved Hybrid Optimization by Genetic } \\
\text { Algorithms) }\end{array}$ & Local & 59 & urbs & $\begin{array}{l}\text { Local, Regional, } \\
\text { National }\end{array}$ \\
\hline 30 & $\begin{array}{c}\text { IRiE } \\
\text { (Integrated Regulating power market in Europe) }\end{array}$ & $\begin{array}{l}26 \text { Areas of Northern } \\
\text { Europe }\end{array}$ & & & \\
\hline
\end{tabular}




\section{Appendix B}

Table A2. Comparison between the 16 selected modelling tools (Part 1). Adapted from [98] and [100].

\begin{tabular}{|c|c|c|c|c|c|}
\hline Serial & Modelling Tools & Objective & Approach & Modelling Horizon & Spatial Coverage \\
\hline 1 & Calliope & $\begin{array}{l}\text { Investment and Operation Decision } \\
\text { Support }\end{array}$ & Bottom-up & Unlimited & User-defined \\
\hline 2 & DESSTinEE & $\begin{array}{l}\text { Scenario, Investment and Operation } \\
\text { Decision Support }\end{array}$ & Bottom-up & 2050 & National, Continental \\
\hline 3 & Dispa-SET & $\begin{array}{l}\text { Investment and Operation Decision } \\
\text { Support }\end{array}$ & - & Typically 1 year & $\begin{array}{l}\text { NUTS1 (Nomenclature of } \\
\text { Territorial Units for Statistics 1) }\end{array}$ \\
\hline 4 & ELMOD & $\begin{array}{l}\text { Investment and Operation Decision } \\
\text { Support }\end{array}$ & Bottom-up & Typically 1 year & Germany, Europe \\
\hline 5 & ficus & $\begin{array}{l}\text { Investment and Operation Decision } \\
\text { Support }\end{array}$ & Bottom-up & 1 year & National, Local \\
\hline 6 & LEAP & Scenario & Hybrid & Typically 20 to 50 years & National \\
\hline 7 & LUSYM & Operation Decision Support & Bottom-up & Daily, Weekly and Yearly & National, Continental \\
\hline 8 & MEDEAS & $\begin{array}{l}\text { CO2 equivalent emissions, energy, social, } \\
\text { economic costs, RE-share }\end{array}$ & Top-down & 1 year & Global, Continents, Nations \\
\hline 9 & Oemof & $\begin{array}{l}\text { Investment and/or Operation Decision } \\
\text { Support, Scenario }\end{array}$ & $\begin{array}{l}\text { Top-down, Bottom-up, } \\
\text { Hybrid }\end{array}$ & Depending on application & Depending on application \\
\hline 10 & OSeMOSYS & Investment Decision Support & Bottom-up & User-defined & Community - Continental \\
\hline 11 & PowerGAMA & Investment Decision support and Scenario & Bottom-up & Typically 1 year & Regional, National \\
\hline 12 & PyPSA & $\begin{array}{l}\text { Investment and Operation Decision } \\
\text { Support, Power System Analysis }\end{array}$ & Bottom-up & 1 year & National \\
\hline 13 & RETScreen & $\begin{array}{l}\text { Investment Decision Support and } \\
\text { Scenario }\end{array}$ & Hybrid & Max 100 years & All \\
\hline 14 & SIREN & Scenario & Bottom-up & 1 year & Regional, National \\
\hline 15 & SWITCH & $\begin{array}{l}\text { Investment and Operation Decision } \\
\text { Support }\end{array}$ & Bottom-up & User-defined & Regional, National \\
\hline 16 & urbs & $\begin{array}{c}\text { Investment and Operation Decision } \\
\text { Support }\end{array}$ & Bottom-up & User-defined & Local, Regional, National \\
\hline
\end{tabular}


Table A3. Comparison between the 16 selected modelling tools (Part 2). Adapted from [98] and [100].

\begin{tabular}{|c|c|c|c|c|c|c|c|}
\hline Serial & $\begin{array}{l}\text { Modelling } \\
\text { Tools }\end{array}$ & $\begin{array}{c}\text { Conventional } \\
\text { Generation }\end{array}$ & $\begin{array}{l}\text { Renewable } \\
\text { Generation }\end{array}$ & Storage Inclusion & Grid & Commodity & Demand Sectors \\
\hline 1 & Calliope & All & All & All & $\begin{array}{l}\text { Net Transfer Capacity } \\
\text { (NTC) }\end{array}$ & $\begin{array}{l}\text { Electricity, Hydrogen, Heat and } \\
\text { Fuels }\end{array}$ & Aggregated \\
\hline 2 & DESSTinEE & All & All & $\begin{array}{l}\text { Pumped Hydro } \\
\text { Storage }\end{array}$ & NTC & Electricity & $\begin{array}{l}\text { Building, Transport and } \\
\text { Industry }\end{array}$ \\
\hline 3 & Dispa-SET & All & All & All & NTC & Electricity, Heat & Aggregated \\
\hline 4 & ELMOD & All & All & All & $\begin{array}{l}\text { Transmission, DC load } \\
\text { flow }\end{array}$ & Electricity, Heat & Aggregated \\
\hline 5 & ficus & All & All & All & Import, Export & Any commodity & Aggregated \\
\hline 6 & LEAP & All & All & All & None & Electricity and heat & $\begin{array}{l}\text { Building, Transport and } \\
\text { Industry }\end{array}$ \\
\hline 7 & LUSYM & All & All & All & $\begin{array}{l}\text { Linearised DC Power } \\
\text { Flow }\end{array}$ & Electricity & Aggregated \\
\hline 8 & MEDEAS & All & All & - & - & $\begin{array}{l}\text { Electricity, Heat, Liquid fuels, } \\
\text { Gas, Solid fuels }\end{array}$ & Aggregated \\
\hline 9 & Oemof & All & All & All & Import, Export, NTC & $\begin{array}{l}\text { Electricity, Heat, Natural } \\
\text { synthetic gas, hydrogen plus all } \\
\text { primary energy sources }\end{array}$ & $\begin{array}{l}\text { Building, transport and } \\
\text { industry }\end{array}$ \\
\hline 10 & OSeMOSYS & All & All & All & None & Electricity & Aggregated \\
\hline 11 & PowerGAMA & All & All & All & $\begin{array}{l}\text { Linearised Optimal } \\
\text { Power Flow }\end{array}$ & Electricity & Aggregated \\
\hline 12 & PyPSA & All & All & All & $\begin{array}{l}\text { Non-linear, Linear } \\
\text { Power Flow, NTC }\end{array}$ & Any commodity & Aggregated \\
\hline 13 & RETScreen & All & All & Batteries & $\begin{array}{l}\text { Central, Isolated, } \\
\text { Off-Grid }\end{array}$ & Electricity and Heat & $\begin{array}{l}\text { Building, Industry (and } \\
\text { Commercial, Institutional, } \\
\text { residential) }\end{array}$ \\
\hline 14 & SIREN & All & All & All & NTC & Electricity & Aggregated \\
\hline 15 & SWITCH & All & All & All & NTC & $\begin{array}{l}\text { Electricity, Hydroelectric flows, } \\
\text { Electric Vehicles }\end{array}$ & Aggregated \\
\hline 16 & urbs & All & All & All & $\begin{array}{c}\text { NTC (+ Linearized Load } \\
\text { Flow) }\end{array}$ & Any Commodity & Aggregated \\
\hline
\end{tabular}


Table A4. Comparison between the 16 selected modelling tools (Part 3). Adapted from [98] and [100].

\begin{tabular}{|c|c|c|c|c|c|c|}
\hline Serial & Modelling Tools & Demand Elasticity & Costs* & Market Modelling & Emissions & Software \\
\hline 1 & Calliope & Inelastic & $\mathrm{I}, \mathrm{O} \& \mathrm{M}, \mathrm{F}, \mathrm{CO}_{2}$ & Supply-Demand & Any & Python \\
\hline 2 & DESSTinEE & Inelastic & $\mathrm{I}, \mathrm{O} \& \mathrm{M}, \mathrm{F}, \mathrm{CO}_{2}$ & Spot & $\mathrm{CO}_{2}$ & $\begin{array}{l}\text { Excel/Visual Basic for } \\
\text { Applications }\end{array}$ \\
\hline 3 & Dispa-SET & Inelastic & $\mathrm{I}, \mathrm{O} \& \mathrm{M}, \mathrm{F}, \mathrm{CO}_{2}$ & Supply-Demand & $\mathrm{CO}_{2}$ & Python, GAMS \\
\hline 4 & ELMOD & & $\mathrm{I}, \mathrm{O} \& \mathrm{M}, \mathrm{F}, \mathrm{CO}_{2}$ & Supply-Demand & $\mathrm{CO}_{2}$ & GAMS \\
\hline 5 & ficus & Inelastic & $\mathrm{I}, \mathrm{O} \& \mathrm{M}, \mathrm{F}, \mathrm{CO}_{2}$ & Supply-Demand & Any & Python \\
\hline 6 & LEAP & Elastic & $\mathrm{I}, \mathrm{O} \& \mathrm{M}, \mathrm{F}, \mathrm{CO}_{2}$ & Supply-Demand & Any & Stand-alone \\
\hline 7 & LUSYM & Inelastic & $\mathrm{O} \& \mathrm{M}, \mathrm{F}, \mathrm{CO}_{2}, \mathrm{~B}$ & Supply-Demand & $\mathrm{CO}_{2}$ & GAMS \& Matlab \\
\hline 8 & MEDEAS & & $\mathrm{I}, \mathrm{O} \& \mathrm{M}, \mathrm{F}, \mathrm{CO}_{2}$ & $\begin{array}{l}\text { Post-Keynesian } \\
\text { Approach }\end{array}$ & Any & Python \\
\hline 9 & Oemof & Inelastic & $\mathrm{I}, \mathrm{O} \& \mathrm{M}, \mathrm{F}, \mathrm{CO}_{2}, \mathrm{~T}, \mathrm{~B}$ & Supply-Demand & Any & Python \\
\hline 10 & OSeMOSYS & Inelastic & $\mathrm{I}, \mathrm{O} \& \mathrm{M}, \mathrm{F}, \mathrm{CO}_{2}, \mathrm{~B}$ & Supply-Demand & Any & GNU MathProg \\
\hline 11 & PowerGAMA & Inelastic & Marginal Costs & Supply-Demand & No (but can be computed) & Python \\
\hline 12 & PyPSA & Inelastic & $\begin{array}{l}\text { Capital Cost and } \\
\text { Marginal Cost }\end{array}$ & Supply-Demand & $\mathrm{CO}_{2}$ & Python \\
\hline 13 & RETScreen & Inelastic & $\mathrm{I}, \mathrm{O} \& \mathrm{M}, \mathrm{F}, \mathrm{CO}_{2}, \mathrm{~T}$ & Supply-Demand & GHG Emission Factor & Windows with .NET \\
\hline 14 & SIREN & Inelastic & I, O\&M, F & Supply-Demand & $\mathrm{CO}_{2}$ & Stand-alone \\
\hline 15 & SWITCH & Elastic, Inelastic & $\mathrm{I}, \mathrm{O} \& \mathrm{M}, \mathrm{F}$ & Supply-Demand & $\begin{array}{l}\mathrm{CO}_{2} \text { (optionally including } \\
\text { upstream intensity) }\end{array}$ & Python \\
\hline 16 & urbs & Inelastic & $\mathrm{I}, \mathrm{O} \& \mathrm{M}, \mathrm{F}, \mathrm{CO}_{2}, \mathrm{~B}$ & No & Any & Python \\
\hline
\end{tabular}

${ }^{*} \mathrm{I}=$ Investment, $\mathrm{O \& M}=$ Operation and Maintenance, $\mathrm{F}=$ Fuel, $\mathrm{B}=$ Balancing, $\mathrm{T}=$ Taxes. 


\section{Appendix C}

Table A5. List of Abbreviations.

\begin{tabular}{cccccc}
\hline Serial & Abbreviation & Elaboration & Serial & Abbreviation & Elaboration \\
\hline 1 & CCS & $\begin{array}{c}\text { Carbon Capture and } \\
\text { Storage }\end{array}$ & 13 & Openmod & Open Energy Modelling \\
\hline 2 & CHP & $\begin{array}{c}\text { Combined Heat and } \\
\text { Power }\end{array}$ & 14 & OTEC & $\begin{array}{c}\text { Ocean Thermal-Energy } \\
\text { Conversion }\end{array}$ \\
\hline 3 & CoP & $\begin{array}{c}\text { Coefficient of } \\
\text { Performance }\end{array}$ & 15 & P2G & Power-to-gas \\
\hline 4 & ENSYSRA & $\begin{array}{c}\text { Energy System in } \\
\text { Transition }\end{array}$ & 16 & P2H & Power-to-heat \\
\hline 5 & EV & Electric Vehicle & 17 & P2L & Power-to-liquid \\
\hline 6 & EU & European Union & 18 & P2X & Power-to-X \\
\hline 7 & GHG & Greenhouse Gas & 19 & PV & Photovoltaic \\
\hline 8 & KWH & Kilowatt-hour & 20 & RES & $\begin{array}{c}\text { Renewable Energy } \\
\text { Sources }\end{array}$ \\
\hline 9 & LP & Linear Programming & 21 & SC & Sector Coupling \\
\hline 10 & MILP & $\begin{array}{c}\text { Mixed-Integer Linear } \\
\text { Programming }\end{array}$ & 22 & STET & $\begin{array}{c}\text { Socio-technical Energy } \\
\text { Transition }\end{array}$ \\
\hline 11 & NS & North Sea & 23 & V2G & Vehicle-to-Grid \\
\hline 12 & NTC & Net Transfer Capacity & 24 & UK & United Kingdom \\
\hline
\end{tabular}

\section{References}

1. Pellerin-Carlin, T.; The European Energy Union. Research Handbook on EU Energy Law and Policy; Edward Elgar Publishing: Cheltenham, UK, 2017; pp. 67-102.

2. Jayaraman, T.; Kanitkar, T. The Paris Agreement. Econ. Political Weekly 2016, 51, 10-13.

3. North Sea Map. Available online: https://commons.wikimedia.org/wiki/File:North_Sea_map-en.png (accessed on 21 August 2019).

4. Hajer, M.A.; Pelzer, P. 2050—An Energetic Odyssey: Understanding 'Techniques of Futuring' in the transition towards renewable energy. Energy Res. Soc. Sci. 2018, 44, 222-231. [CrossRef]

5. Hybrid Offshore Energy Transition Options-The Merits and Challenges of Combining Offshore System Integration Options; Synthesis Paper NSE II. 2019, pp. 1-23. Available online: https://www.north-sea-energy. eu/documents/NSE2\%20\%20Deliverable\%20Synthesis\%20paper.pdf (accessed on 21 August 2019).

6. Europe Powered by Green Energy-How the North Seas Can Lead the Change; Paper by Ørsted A/S, Denmark. 2017, pp. 1-16. Available online: https://orstedcdn.azureedge. net/-/media/WWW/Docs/Corp/COM/About-us/North-seas/rsted-Paper-01---Europe-Poweredby-Green-Energy_UK.ashx?la=en\&hash=2CD90870F9B48DF55F2DB3EF51DD6D411873A31F\% 2C2CD90870F9B48DF55F2DB3EF51DD6D411873A31F\&rev=0568da28b1954084b341f2f1827323d7 (accessed on 21 August 2019).

7. UNFCCC. Greenhouse Gas Inventory Data-Detailed Data by Party. 2017. Available online: http: //di.unfccc.int/detailed_data_by_party (accessed on 21 August 2019).

8. Climate Watch; World Resources Institute: Washington, DC, USA, 2018. Available online: https://www. climatewatchdata.org (accessed on 21 August 2019).

9. Interreg North Sea Region Project Database. Available online: http://projects.northsearegion.eu/vb/overview/ (accessed on 21 August 2019).

10. Energy Systems in Transition. Available online: https://ensystra.eu/ (accessed on 21 August 2019).

11. Sector Coupling-Shaping an Integrated Renewable Energy System. 2018. Available online: https://www. cleanenergywire.org/factsheets/sector-coupling-shaping-integrated-renewable-power-system (accessed on 22 August 2019). 
12. Blundell, D. How Efficient Is a Heat Pump? Available online: https://help.leonardo-energy.org/hc/en-us/ articles/203047881-How-efficient-is-a-heat-pump (accessed on 22 August 2019).

13. Bundesministerium für Wirtschaft und Energie. Was Bedeutet "Sektorkopplung"? Available online: https: //www.bmwi-energiewende.de/EWD/Redaktion/Newsletter/2016/14/Meldung/direkt-erklaert.html (accessed on 22 August 2019).

14. A Collective View of the Storage Market. Presentation by Christian Brennig, BVES-German Energy Storage Association. Available online: https://www.german-energy-solutions.de/GES/Redaktion/EN/Publications/ Presentations/180718-presentation-ir-norway-bves.pdf (accessed on 22 August 2019).

15. Lehmann, H. Energy-Rich Japan; ISSI Report. 2003. Available online: http://www.energyrichjapan.info/pdf/ EnergyRichJapan_summary.pdf (accessed on 24 August 2019).

16. Lund, H.; Mathiesen, B.V. Energy system analysis of $100 \%$ renewable energy systems-The case of Denmark in years 2030 and 2050. Energy 2009, 34, 524-531. [CrossRef]

17. Lund, H.; Möller, B.; Mathiesen, B.V.; Dyrelund, A. The role of district heating in future renewable energy systems. Energy 2010, 35, 1381-1390. [CrossRef]

18. Lund, H.; Kempton, W. Integration of renewable energy into the transport and electricity sectors through V2G. Energy Policy 2008, 36, 3578-3587. [CrossRef]

19. Madlener, R.; Kowalski, K.; Stagl, S. New ways for the integrated appraisal of national energy scenarios: The case of renewable energy use in Austria. Energy Policy 2007, 35, 6060-6074. [CrossRef]

20. Sørensen, B. A renewable energy and hydrogen scenario for northern Europe. Int. J. Energy Res. 2008, 32, 471-500. [CrossRef]

21. Krajačić, G.; Martins, R.; Busuttil, A.; Duić, N.; da Graça Carvalho, M. Hydrogen as an energy vector in the islands' energy supply. Int. J. Hydrogen Energy 2008, 33, 1091-1103. [CrossRef]

22. Kim, J.; Moon, I. The role of hydrogen in the road transportation sector for a sustainable energy system: A case study of Korea. Int. J. Hydrogen Energy 2008, 33, 7326-7337. [CrossRef]

23. Mason, I.; Page, S.; Williamson, A. A 100\% renewable electricity generation system for New Zealand utilising hydro, wind, geothermal and biomass resources. Energy Policy 2010, 38, 3973-3984. [CrossRef]

24. Zervos, A.; Lins, C.; Muth, J. RE-Thinking 2050: A 100\% Renewable Energy Vision for the European Union; EREC: Brussels, Belgium, 2010.

25. Connolly, D.; Lund, H.; Mathiesen, B.V.; Leahy, M. The first step towards a $100 \%$ renewable energy-system for Ireland. Appl. Energy 2011, 88, 502-507. [CrossRef]

26. Krajačić, G.; Duić, N.; Zmijarević, Z.; Mathiesen, B.V.; Vučinić, A.A.; da Graça Carvalho, M. Planning for a $100 \%$ independent energy system based on smart energy storage for integration of renewables and CO2 emissions reduction. Appl. Therm. Eng. 2011, 31, 2073-2083. [CrossRef]

27. Liu, W.; Lund, H.; Mathiesen, B.V.; Zhang, X. Potential of renewable energy systems in China. Appl. Energy 2011, 88, 518-525. [CrossRef]

28. Ćosić, B.; Krajačić, G.; Duić, N. A 100\% renewable energy system in the year 2050: The case of Macedonia. Energy 2012, 48, 80-87. [CrossRef]

29. Henning, H.-M.; Palzer, A. A comprehensive model for the German electricity and heat sector in a future energy system with a dominant contribution from renewable energy technologies—Part I: Methodology. Renew. Sustain. Energy Rev. 2014, 30, 1003-1018. [CrossRef]

30. Palzer, A.; Henning, H.-M. A comprehensive model for the German electricity and heat sector in a future energy system with a dominant contribution from renewable energy technologies-Part II: Results. Renew. Sustain. Energy Rev. 2014, 30, 1019-1034. [CrossRef]

31. Garmsiri, S.; Rosen, M.; Smith, G. Integration of Wind Energy, Hydrogen and Natural Gas Pipeline Systems to Meet Community and Transportation Energy Needs: A Parametric Study. Sustainability 2014, 6, 2506-2526. [CrossRef]

32. Qadrdan, M.; Abeysekera, M.; Chaudry, M.; Wu, J.; Jenkins, N. Role of power-to-gas in an integrated gas and electricity system in Great Britain. Int. J. Hydrogen Energy 2015, 40, 5763-5775. [CrossRef]

33. Teng, F.; Aunedi, M.; Strbac, G. Benefits of flexibility from smart electrified transportation and heating in the future UK electricity system. Appl. Energy 2016, 167, 420-431. [CrossRef]

34. Guandalini, G.; Robinius, M.; Grube, T.; Campanari, S.; Stolten, D. Long-term power-to-gas potential from wind and solar power: A country analysis for Italy. Int. J. Hydrogen Energy 2017, 42, 13389-13406. [CrossRef] 
35. Delucchi, M.A.; Jacobson, M.Z. Providing all global energy with wind, water, and solar power, Part II: Reliability, system and transmission costs, and policies. Energy Policy 2011, 39, 1170-1190. [CrossRef]

36. Connolly, D.; Mathiesen, B.V. A technical and economic analysis of one potential pathway to a $100 \%$ renewable energy system. Int. J. Sustain. Energy Plan. Manag. 2014, 1, 7-28.

37. Mathiesen, B.V.; Lund, H.; Connolly, D.; Wenzel, H.; Østergaard, P.A.; Möller, B.; Nielsen, S.; Ridjan, I.; Karnøe, P.; Sperling, K. Smart Energy Systems for coherent $100 \%$ renewable energy and transport solutions. Appl. Energy 2015, 145, 139-154. [CrossRef]

38. Nastasi, B.; Lo Basso, G. Hydrogen to link heat and electricity in the transition towards future Smart Energy Systems. Energy 2016, 110, 5-22. [CrossRef]

39. Samsatli, S.; Staffell, I.; Samsatli, N.J. Optimal design and operation of integrated wind-hydrogen-electricity networks for decarbonising the domestic transport sector in Great Britain. Int. J. Hydrogen Energy 2016, 41, 447-475. [CrossRef]

40. Rogge, M.; Wollny, S.; Sauer, D. Fast Charging Battery Buses for the Electrification of Urban Public Transport-A Feasibility Study Focusing on Charging Infrastructure and Energy Storage Requirements. Energies 2015, 8, 4587-4606. [CrossRef]

41. Buttler, A.; Spliethoff, H. Current status of water electrolysis for energy storage, grid balancing and sector coupling via power-to-gas and power-to-liquids: A review. Renew. Sustain. Energy Rev. 2018, 82, 2440-2454. [CrossRef]

42. Schaber, K. Integration of Variable Renewable Energies in the European Power System: A Model-Based Analysis of Transmission Grid Extensions and Energy Sector Coupling. Ph.D. Thesis, Technische Universität München, München, Germany, 2014.

43. Gils, H.; Simon, S.; Soria, R. 100\% renewable energy supply for Brazil-The role of sector coupling and regional development. Energies 2017, 10, 1859. [CrossRef]

44. Liu, W.; Hu, W.; Lund, H.; Chen, Z. Electric vehicles and large-scale integration of wind power-The case of Inner Mongolia in China. Appl. Energy 2013, 104, 445-456. [CrossRef]

45. Liu, W.; Lund, H.; Mathiesen, B.V. 2013. Modelling the transport system in China and evaluating the current strategies towards the sustainable transport development. Energy Policy 2013, 58, 347-357. [CrossRef]

46. Mathiesen, B.V.; Lund, H.; Karlsson, K. 100\% Renewable energy systems, climate mitigation and economic growth. Appl. Energy 2011, 88, 488-501. [CrossRef]

47. Lund, H.; Werner, S.; Wiltshire, R.; Svendsen, S.; Thorsen, J.E.; Hvelplund, F.; Mathiesen, B.V. 4th Generation District Heating (4GDH): Integrating smart thermal grids into future sustainable energy systems. Energy 2014, 68, 1-11. [CrossRef]

48. Lund, H.; Andersen, A.N.; Østergaard, P.A.; Mathiesen, B.V.; Connolly, D. From electricity smart grids to smart energy systems-A market operation based approach and understanding. Energy 2012, 42, 96-102. [CrossRef]

49. Connolly, D.; Lund, H.; Mathiesen, B.V.; Werner, S.; Möller, B.; Persson, U.; Boermans, T.; Trier, D.; Østergaard, P.A.; Nielsen, S. Heat Roadmap Europe: Combining district heating with heat savings to decarbonise the EU energy system. Energy Policy 2014, 65, 475-489. [CrossRef]

50. Xiong, W.; Wang, Y.; Mathiesen, B.V.; Lund, H.; Zhang, X. Heat roadmap China: New heat strategy to reduce energy consumption towards 2030. Energy 2015, 81, 274-285. [CrossRef]

51. David, A.; Mathiesen, B.V.; Averfalk, H.; Werner, S.; Lund, H. Heat roadmap Europe: Large-scale electric heat pumps in district heating systems. Energies 2017, 10, 578. [CrossRef]

52. Connolly, D.; Lund, H.; Mathiesen, B.V. Smart Energy Europe: The technical and economic impact of one potential 100\% renewable energy scenario for the European Union. Renew. Sustain. Energy Rev. 2016, 60, 1634-1653. [CrossRef]

53. Lund, H.; Østergaard, P.A.; Connolly, D.; Ridjan, I.; Mathiesen, B.V.; Hvelplund, F.; Thellufsen, J.Z.; Sorknæs, P. Energy storage and smart energy systems. Int. J. Sustain. Energy Plan. Manag. 2016, 11, 3-14.

54. Brown, T.W.; Bischof-Niemz, T.; Blok, K.; Breyer, C.; Lund, H.; Mathiesen, B.V. Response to 'Burden of proof: A comprehensive review of the feasibility of $100 \%$ renewable-electricity systems'. Renew. Sustain. Energy Rev. 2018, 92, 834-847. [CrossRef]

55. Lund, H.; Østergaard, P.A.; Connolly, D.; Mathiesen, B.V. Smart energy and smart energy systems. Energy 2017, 137, 556-565. [CrossRef] 
56. Lund, H. Renewable heating strategies and their consequences for storage and grid infrastructures comparing a smart grid to a smart energy systems approach. Energy 2018, 151, 94-102. [CrossRef]

57. Robinius, M.; Otto, A.; Heuser, P.; Welder, L.; Syranidis, K.; Ryberg, D.S.; Grube, T.; Markewitz, P.; Peters, R.; Stolten, D. Linking the Power and Transport Sectors-Part 1: The Principle of Sector Coupling. Energies 2017, 10, 956. [CrossRef]

58. Robinius, M.; Otto, A.; Syranidis, K.; Ryberg, D.S.; Heuser, P.; Welder, L.; Grube, T.; Markewitz, P.; Tietze, V.; Stolten, D. Linking the Power and Transport Sectors-Part 2: Modelling a Sector Coupling Scenario for Germany. Energies 2017, 10, 957. [CrossRef]

59. Brown, T.; Schlachtberger, D.; Kies, A.; Schramm, S.; Greiner, M. 2018. Synergies of sector coupling and transmission reinforcement in a cost-optimised, highly renewable European energy system. Energy 2018, 160, 720-739. [CrossRef]

60. Charpentier, J.P. A Review of Energy Models No. 1 RR-74-10; IIASA Research Report; IIASA: Laxenburg, Austria, 1974.

61. Beaujean, J.M.; Charpentier, J.P.; Nakicenovic, N. Global and international energy models: A survey. Annu. Rev. Energy 1977, 2, 153-170. [CrossRef]

62. Meier, P.M. Energy Systems Analysis for Developing Countries; Springer: Berlin/Heidelberg, Germany, 1984.

63. Markandya, A. Environmental costs and power system planning. Util. Policy 1990, 1, 13-27. [CrossRef]

64. Grubb, M.; Edmonds, J.; Ten Brink, P.; Morrison, M. The costs of limiting fossil-fuel CO2 emissions: A survey and analysis. Annu. Rev. Energy Environ. 1993, 18, 397-478. [CrossRef]

65. Shukla, P.R. Greenhouse gas models and abatement costs for developing nations: A critical assessment. Energy Policy 1995, 8, 677-687. [CrossRef]

66. Bhattacharyya, S.C. Applied general equilibrium models for energy studies: A survey. Energy Econ. 1996, 18, 145-164. [CrossRef]

67. Krause, F. The costs of mitigating carbon emissions: A review of methods and findings from European studies. Energy Policy 1996, 24, 899-915. [CrossRef]

68. Hourcade, J.C.; Robinson, J. Mitigating factors: Assessing the costs of reducing GHG emissions. Energy Policy 1996, 24, 863-873. [CrossRef]

69. Kelly, D.L.; Kolstad, C.D. Integrated assessment models for climate change control. Int. Yearb. Environ. Resour. Econ. 1999, 171-197.

70. Van Beeck, N. Classification of Energy Models; Tilburg University, Faculty of Economics and Business Administration: Tilburg, The Netherlands, 2000.

71. Jebaraj, S.; Iniyan, S. A review of energy models. Renew. Sustain. Energy Rev. 2006, 10, 281-311. [CrossRef]

72. Connolly, D.; Lund, H.; Mathiesen, B.V.; Leahy, M. A review of computer tools for analysing the integration of renewable energy into various energy systems. Appl. Energy 2010, 87, 1059-1082. [CrossRef]

73. Pandey, R. Energy policy modelling: Agenda for developing countries. Energy Policy 2002, 30, 97-106. [CrossRef]

74. Bahn, O.; Haurie, A.; Zachary, D.S. Mathematical modeling and simulation methods in energy systems. In Groupe D'études Et De Rech. En Anal. Des Décisions; HEC Montréal: Montréal, QC, Canada, 2004.

75. Nakata, T. Energy-economic models and the environment. Prog. Energy Combust. Sci. 2004, 30, 417-475. [CrossRef]

76. Ventosa, M.; Barllo, A.; Ramos, A.; Rivier, M. Electricity market modeling trends. Energy Policy 2005, 33, 897-913. [CrossRef]

77. Urban, F.R.M.J.; Benders, R.M.J.; Moll, H.C. Modelling energy systems for developing countries. Energy Policy 2007, 35, 3473-3482. [CrossRef]

78. Hiremath, R.B.; Shikha, S.; Ravindranath, N.H. Decentralized energy planning; modeling and application-A review. Renew. Sustain. Energy Rev. 2007, 11, 729-752. [CrossRef]

79. Sensfuß, F.; Ragwitz, M. An agent-based simulation platform as support tool for the analysis of the interactions of renewable electricity generation with the electricity and CO2 market. In Proceedings of the New methods for Energy Market Modelling, Karlsruhe, Germany, 26 October 2007; pp. 63-76.

80. Van Ruijven, B.; Urban, F.; Benders, R.M.; Moll, H.C.; Van Der Sluijs, J.P.; De Vries, B.; Van Vuuren, D.P. Modeling energy and development: An evaluation of models and concepts. World Dev. 2008, 36, 2801-2821. [CrossRef] 
81. Möst, D.; Keles, D. A survey of stochastic modelling approaches for liberalised electricity markets. Eur. J. Oper. Res. 2010, 207, 543-556. [CrossRef]

82. Foley, A.M.; Gallachóir, B.Ó.; Hur, J.; Baldick, R.; McKeogh, E.J. A strategic review of electricity systems models. Energy 2010, 35, 4522-4530. [CrossRef]

83. Bhattacharyya, S.C.; Timilsina, G.R. A review of energy system models. Int. J. Energy Sect. Manag. 2010, 4, 494-518. [CrossRef]

84. Bazmi, A.A.; Zahedi, G. Sustainable energy systems: Role of optimization modeling techniques in power generation and supply-A review. Renew. Sustain. Energy Rev. 2011, 15, 3480-3500. [CrossRef]

85. Keirstead, J.; Jennings, M.; Sivakumar, A. A review of urban energy system models: Approaches, challenges and opportunities. Renew. Sustain. Energy Rev. 2012, 16, 3847-3866. [CrossRef]

86. DeCarolis, J.F.; Hunter, K.; Sreepathi, S. The case for repeatable analysis with energy economy optimization models. Energy Econ. 2012, 34, 1845-1853. [CrossRef]

87. Suganthi, L.; Samuel, A.A. Energy models for demand forecasting-A review. Renew. Sustain. Energy Rev. 2012, 16, 1223-1240. [CrossRef]

88. Hedenus, F.; Johansson, D.; Lindgren, K. A critical assessment of Energy-economy-climate models for policy analysis. J. Appl. Econ. Bus. Res. 2013, 3, 118-132.

89. Pfenninger, S.; Hawkes, A.; Keirstead, J. Energy systems modeling for twenty-first century energy challenges. Renew. Sustain. Energy Rev. 2014, 33, 74-86. [CrossRef]

90. Olanrewaju, O.A.; Jimoh, A.A. Review of energy models to the development of an efficient industrial energy model. Renew. Sustain. Energy Rev. 2014, 30, 661-671. [CrossRef]

91. Li, F.G.; Trutnevyte, E.; Strachan, N. A review of socio-technical energy transition (STET) models. Technol. Forecast. Soc. Chang. 2015, 100, 290-305. [CrossRef]

92. Sinha, S.; Chandel, S.S. Review of recent trends in optimization techniques for solar photovoltaic-wind based hybrid energy systems. Renew. Sustain. Energy Rev. 2015, 50, 755-769. [CrossRef]

93. Després, J.; Hadjsaid, N.; Criqui, P.; Noirot, I. Modelling the impacts of variable renewable sources on the power sector: Reconsidering the typology of energy modelling tools. Energy 2015, 80, 486-495. [CrossRef]

94. Van Beuzekom, I.; Gibescu, M.; Slootweg, J.G. A review of multi-energy system planning and optimization tools for sustainable urban development. In Proceedings of the 2015 IEEE Eindhoven Power Tech, Eindhoven, Netherlands, 29 June-2 July 2015; pp. 1-7.

95. Hall, L.M.; Buckley, A.R. A review of energy systems models in the UK: Prevalent usage and categorisation. Appl. Energy 2016, 169, 607-628. [CrossRef]

96. Mahmud, K.; Town, G.E. A review of computer tools for modeling electric vehicle energy requirements and their impact on power distribution networks. Appl. Energy 2016, 172, 337-359. [CrossRef]

97. Sola, A.; Corchero, C.; Salom, J.; Sanmarti, M. Simulation Tools to Build Urban-Scale Energy Models: A Review. Energies 2018, 11, 3269. [CrossRef]

98. Ringkjøb, H.K.; Haugan, P.M.; Solbrekke, I.M. A review of modelling tools for energy and electricity systems with large shares of variable renewables. Renew. Sustain. Energy Rev. 2018, 96, 440-459. [CrossRef]

99. Lopion, P.; Markewitz, P.; Robinius, M.; Stolten, D. A review of current challenges and trends in energy systems modeling. Renew. Sustain. Energy Rev. 2018, 96, 156-166. [CrossRef]

100. Open Models. Available online: https://wiki.openmod-initiative.org/wiki/Open_Models\#List_of_models (accessed on 3 September 2019).

101. Openmod in a Nutshell. Available online: http://openmod-initiative.org/manifesto (accessed on 3 September 2019).

102. Pfenninger, S.; Hirth, L.; Schlecht, I.; Schmid, E.; Wiese, F.; Brown, T.; Davis, C.; Gidden, M.; Heinrichs, H.; Heuberger, C.; et al. 2018. Opening the black box of energy modelling: Strategies and lessons learned. Energy Strategy Rev. 2018, 19, 63-71. [CrossRef]

103. Openmod Open Energy Modelling Initiative. Available online: https://www.openmod-initiative.org/ (accessed on 3 September 2019).

104. Calliope: A Multi-Scale Energy Systems Modelling Framework. Available online: https://sites.google.com/ site/2050desstinee/ (accessed on 30 October 2019).

105. 2050 Desstinee. Available online: https://calliope.readthedocs.io/en/stable/ (accessed on 30 October 2019).

106. The Dispa-SET Model. Available online: http://www.dispaset.eu/en/latest/index.html (accessed on 30 October 2019). 
107. Energy, Transportation, Environment Department Models. Available online: https://www.diw.de/en/diw_01. c.599753.en/models.html (accessed on 30 October 2019).

108. Ficus: A (Mixed Integer) Linear Optimisation Model for Local Energy Systems. Available online: https: //ficus.readthedocs.io/en/latest/ (accessed on 30 October 2019).

109. LEAP. Available online: https://www.energycommunity.org/default.asp?action=introduction (accessed on 30 October 2019).

110. Van den Bergh, K.; Bruninx, K.; Delarue, E.; D’haeseleer, W. LUSYM: A unit commitment model formulated as a mixed-integer linear program. Ku Leuventme Branch Work. Pap. 2016, 7, 1-20.

111. MEDEAS-Modelling the Energy Development under Environmental and Socioeconomic Constraints. Available online: https://www.medeas.eu/ (accessed on 31 October 2019).

112. Oemof-Open Energy Modelling Framework. Available online: https://oemof.org/ (accessed on 4 September 2019).

113. Oemof Community (on Github). Available online: https://github.com/oemof (accessed on 4 September 2019).

114. Oemof Documentation. Available online: https://oemof.readthedocs.io/en/stable/ (accessed on 4 September 2019).

115. OSeMOSYS Documentation. Available online: https://osemosys.readthedocs.io/en/latest/index.html (accessed on 31 October 2019).

116. Svendsen, H.G.; Spro, O.C. PowerGAMA: A new simplified modelling approach for analyses of large interconnected power systems, applied to a 2030 Western Mediterranean case study. J. Renew. Sustain. Energy 2016, 8, 055501. [CrossRef]

117. PyPSA. Available online: https://pypsa.org/ (accessed on 31 October 2019).

118. RETScreen. Available online: https://www.nrcan.gc.ca/energy/retscreen/7465 (accessed on 31 October 2019).

119. Modelling Overview_The SIREN Toolkit and More. Available online: https://www.sen.asn.au/modelling overview (accessed on 31 October 2019).

120. Switch Power System Planning Model. Available online: http://switch-model.org/ (accessed on 31 October 2019).

121. urbs: A Linear Optimisation Model for Distributed Energy Systems. Available online: https://urbs.readthedocs. io/en/latest/index.html (accessed on 31 October 2019).

122. Bird, L.; Milligan, M.; Lew, D. Integrating Variable Renewable Energy: Challenges and Solutions (No. NREL/TP-6A20-60451); National Renewable Energy Lab.(NREL): Golden, CO, USA, 2013.

123. Maruf, M.N.I.; Munoz, L.H.; Nguyen, P.H.; Ferreira, H.L.; Kling, W.L. An enhancement of agent-based power supply-demand matching by using ann-based forecaster. In Proceedings of the IEEE PES ISGT Europe, Lyngby, Denmark, 6-9 October 2013; pp. 1-5.

124. Zunnurain, I.; Maruf, M.; Rahman, M.; Shafiullah, G.M. Implementation of advanced demand side management for microgrid incorporating demand response and home energy management system. Infrastructures 2018, 3, 50. [CrossRef]

125. Rahman, M.; Cecchi, V.; Miu, K. Power handling capabilities of transmission systems using a temperature-dependent power flow. Electr. Power Syst. Res. 2019, 169, 241-249. [CrossRef]

126. Rahman, M.; Braun, C.; Cecchi, V. Determination of Transmission Line Power Transfer Capabilities Using Temperature Dependent Continuation Power Flow. In Proceedings of the 2018 IEEE Power \& Energy Society General Meeting (PESGM), Portland, OR, USA, 5-10 August 2018; pp. 1-5.

127. Hilpert, S.; Kaldemeyer, C.; Krien, U.; Günther, S.; Wingenbach, C.; Plessmann, G. The Open Energy Modelling Framework (oemof)-A new approach to facilitate open science in energy system modelling. Energy Strategy Rev. 2018, 22, 16-25. [CrossRef]

128. Möller, C.; Kuhnke, K.; Reckzugel, M.; Pfisterer, H.-J.; Rosenberger, S. Energy Storage Potential in the Northern German Region Osnabrück-steinfurt. In Proceedings of the IEEE International Energy and Sustainability Conference (IESC), Cologne, Germany, 30 June-1 July 2016; pp. 1-7.

129. Müller;, U.P.; Cussmann, I.; Wingenbach, C.; Wendiggensen, J. Power Flow Simulations within an Open Data Model of a High Voltage Grid. In Advances and New Trends in Environmental Informatics; Progress in IS; Springer: Cham, Switzerland, 2017; pp. 181-193.

130. Bunke, W.D.; Christ, M.; Degel, M. VerNetzen: Sozial-ökologische und technisch-ökonomische Modellierung von Entwicklungspfaden der Energiewende. Wissenschaftsdialog 2014, 107-128, The report is from a Workshop.

131. Wingenbach, C.; Hilpert, S.; Günther, S. openMod.SH-ein regionales Strom-Wärme-Modell für Schleswig-Holstein basierend auf open source und open data. In Proceedings of the 14th Symposium on Energy Innovation, Graz, Austria, 10-12 February 2016. 
132. Kaldemeyer, C.; Boysen, C.; Tuschy, I. Compressed Air Energy Storage in the German Energy System-Status Quo \& Perspectives. Energy Procedia 2016, 99, 298-313.

133. Arnhold, O.; Fleck, M.; Goldammer, K.; Grüger, F.; Hoch, O.; Schachler, B. Transformation of the German energy and transport sector-a national analysis. In Netzintegration der Elektromobilität; Springer: Wiesbaden, Germany, 2017; pp. 9-21.

134. Renpass-Renewable Energy Pathway Simulation System (on Github). Available online: https://github.com/ znes/renpass (accessed on 5 September 2019).

135. appBBB-An Oemof Application to Model the Heat and Power Systems of Brandenburg and Berlin (On Github). Available online: https://github.com/rl-institut/appBBB (accessed on 5 September 2019).

136. HESYSOPT-A Heating System Simulation Tool (On Github). Available online: https://github.com/znes/ HESYSOPT (accessed on 5 September 2019).

137. Hilpert, S. HESYSOPT-An open source tool to support district heating system flexibilisation. In Environmental Informatics-Stability, Continuity, Innovation: Current Trends and Future Perspectives Based On 30 Years of History; Shaker Verlag Publishing House: Aachen, Germany, 2016; pp. 361-366.

138. Wingenbach, C.; Hilpert, S.; Günther, S. The core concept of the Open Energy Modelling Framework (oemof). In Environmental Informatics-Stability, Continuity, Innovation: Current Trends and Future Perspectives Based On 30 Years of History; Shaker Verlag Publishing House: Aachen, Germany, 2016; pp. 361-366.

(C) 2019 by the author. Licensee MDPI, Basel, Switzerland. This article is an open access article distributed under the terms and conditions of the Creative Commons Attribution (CC BY) license (http://creativecommons.org/licenses/by/4.0/). 